\section{(A) Check for updates}

Cite this: Green Chem., 2020, 22 3358

Received 8th April 2020, Accepted 13th May 2020 DOI: $10.1039 / \mathrm{dOgc01247e}$ rsc.li/greenchem

\title{
Making electrochemistry easily accessible to the synthetic chemist
}

\author{
Christiane Schotten, ${ }^{\text {a }}$ Thomas P. Nicholls, (D) a Richard A. Bourne, (D) ${ }^{\mathrm{b}}$ \\ Nikil Kapur, (iD c Bao N. Nguyen (iD ${ }^{c}$ and Charlotte E. Willans (iD *a
}

A significantly renewed interest in synthetic electrochemistry is apparent in the increasing number of publications over the last few years. Electrochemical synthesis offers a mild, green and atom efficient route to interesting and useful molecules, thus avoiding harsh chemical oxidising and reducing agents used in traditional synthetic methods. As such, encouraging broader application of electrochemistry by synthetic chemists should be a priority. Despite the renewed interest there remains a barrier to widespread adoption of this technology derived from the extra knowledge and specialised equipment required. This has led to a knowledge gap between experienced electrochemists and those new in the field. In this tutorial we will bridge the knowledge gap by providing an easily accessible introduction which will enable synthetic chemists new to the field to explore electrochemistry. We will discuss mechanistic considerations, the setup of an electrochemical reaction with all its components, trouble shooting and selected examples from the literature.
\end{abstract}

\section{Introduction}

During the last decade, electrochemistry has received renewed interest as a tool for synthetic chemistry. ${ }^{1-17}$ This is exemplified by whole journal issues being dedicated to synthetic electrochemistry. ${ }^{18,19}$ Electrochemistry offers a very mild and atom efficient method to achieve selective oxidative or reduc-

${ }^{a}$ School of Chemistry, University of Leeds, Leeds LS2 9JT, UK

E-mail: C.Schotten@leeds.ac.uk, C.E.Willans@leeds.ac.uk

${ }^{b}$ School of Chemical and Process Engineering, University of Leeds, Leeds LS2 9JT, UK

${ }^{c}$ School of Mechanical Engineering, University of Leeds, Leeds LS2 9JT, UK

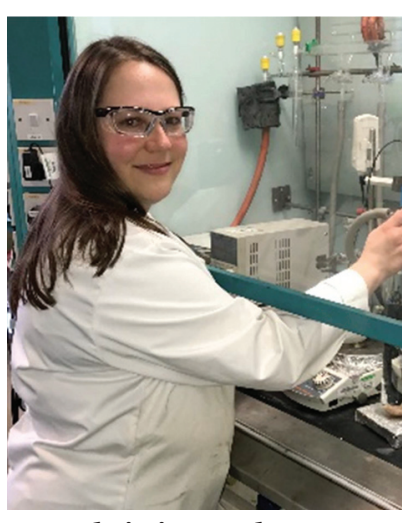

Christiane Schotten
Dr Christiane Schotten graduated with a BSc and MSc from RWTH Aachen University (Germany). During her PhD at Cardiff University (UK), Christiane worked with Dr Duncan Browne on multistep continuous flow processes using diazonium salts. She then was awarded an RSC mobility grant to work with Dr Timothy Noël at Eindhoven University of Technology (Netherlands) on continuous electrochemical synthesis. Christiane is currently working in the group of Dr Charlotte Willans (University of Leeds, UK) as a postdoctoral research assistant on the development of a multifunctional electrochemical flow platform for high-throughput synthesis and optimisation of catalysts.

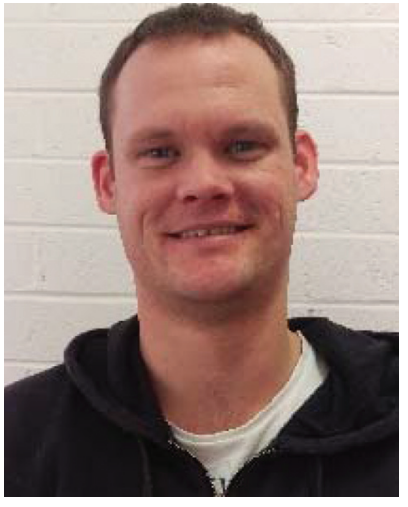

Thomas P. Nicholls
Dr Thomas Nicholls obtained his $\mathrm{PhD}$ in chemistry from the University of Tasmania in 2018 in the lab of Dr Alex Bissember, with research focused on the photophysical and electrochemical characterisation of novel copper-based visible light photocatalysts, and the development of photocatalysed synthetic methodologies enabling the rapid construction of complex organic frameworks. He is currently working in the lab of Dr Charlotte Willans as a postdoctoral research assistant investigating the electrochemical synthesis of inorganic and organometallic complexes and the development of catalytic methodologies using high throughput experimentation. 
tive transformations using electrons as reactants. It therefore avoids the use of other harsh and often toxic chemical reducing and oxidising agents. ${ }^{4,6,15}$ In addition, electrochemistry can offer new reaction pathways that are complimentary to traditional synthetic chemistry procedures and can be particularly interesting for late-stage functionalisation due to its mild and selective nature. ${ }^{10}$ Nonetheless, it is only in the last few years that the synthetic chemistry community has rediscovered this powerful tool for small scale synthetic applications. ${ }^{5,7}$ Its resurgence is in part due to the chemical community being driven towards more sustainable and greener reaction pathways. ${ }^{4,6,15}$ As electrochemistry uses electrons as reactants and a source of energy, the atom economy is usually increased. In addition, due to the highly selective nature, derivatisations such as protection/deprotection can often be avoided.

Despite the many benefits of electrochemistry, the general perception, that specialised equipment and expert knowledge is required, presents a high barrier for chemists to adopting this exciting technique. Even though reading material for nonelectrochemists ${ }^{20-22}$ and recently a 'survival guide'23 are available, we feel the need for an easily accessible, modern introduction to electrochemistry to allow more researchers to explore electrochemistry for synthetic chemistry. We also discuss the benefits of continuous flow electrochemistry, for example as a way to address scale up. In addition, we have summarised possible parameter changes and the influence on the reaction performance.

This tutorial review provides an introduction to electrochemistry and is not designed to be an extensive review of all synthetic electrochemical examples. For further information recent reviews and the references therein are recommended: certain transformations including cross coupling, ${ }^{24-26} \mathrm{CH}$ activation, ${ }^{27-36}$ asymmetric synthesis, ${ }^{14}$ heterocycle formation, ${ }^{37-39}$ arylation, ${ }^{40}$ fluorination, ${ }^{41}$ organometallic

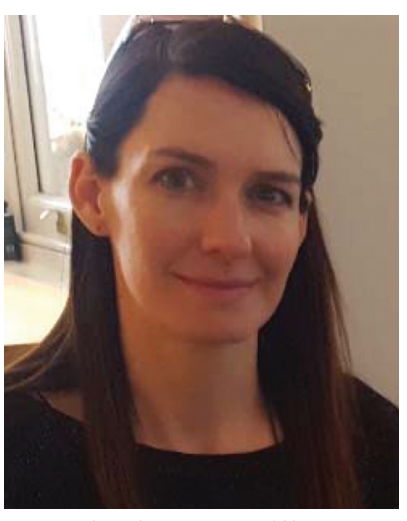

Charlotte E. Willans
Dr Charlotte Willans obtained her MChem from the University of York, conducting a research project at DSM (Netherlands) with Profs Johannes de Vries and André de Vries on palladium-catalysed cross-coupling reactions. She completed her PhD at the University of York working with Prof Francesca Kerton and Dr Jason Lynam on lanthanide catalysis and organophosphorus cages. She completed a postdoctoral position with Prof Jonathan Steed in Durham, working on MOFs and metal-N-heterocyclic carbenes. Charlotte was awarded a Royal Society Dorothy Hodgkin Fellowship which she took to Leeds in 2009. Current research includes electrochemical synthetic methods to metal compounds, flow technology and catalytic and biomedical applications. catalysis, ${ }^{42,43}$ cation pool method, ${ }^{44}$ continuous reactor types, ${ }^{45-55}$ analytical tools ${ }^{56,57}$ and general reviews and perspectives. ${ }^{1-17}$

\section{Terminology}

Power supply - electricity source

Current - movement of electrons ( $I$ in ampere)

Potential - voltage difference between two electrodes, provides energy to move electrons ( $U$ in volt)

Charge - current passed over time ( $Q$ in coulomb)

Electrode - conducting material that carries current into reaction solution

Cathode - reduction electrode

Anode - oxidation electrode

Working electrode - electrode where the reaction of interest is happening (WE)

Counter electrode - electrode opposite to working electrode (CE)

Counter reaction - reaction on the counter electrode

Cyclic voltammetry - an electrochemical analytical tool (CV)

Overpotential - additional potential required, dependent on $e . g$. the electrode material

Standard potential - potential of a redox reaction under standard conditions

\section{Principles of synthetic electrochemical reactions}

A simple electrochemical setup is comprised of a reaction vessel with a power supply (1), a reaction solution (2) and two electrodes (3 and 4) which are connected to the power supply (Fig. 1). The reaction solution consists of a solvent, the substrate(s) and, if necessary, an electrolyte and additives. Separate electrochemical reactions will happen on both electrodes. The anode (3, red) is defined as the oxidation electrode, the cathode $(4$, black) as the reduction electrode. The arrows on the connections to the power supply indicate the direction of electron flow, from the anode to the cathode. Both reac-

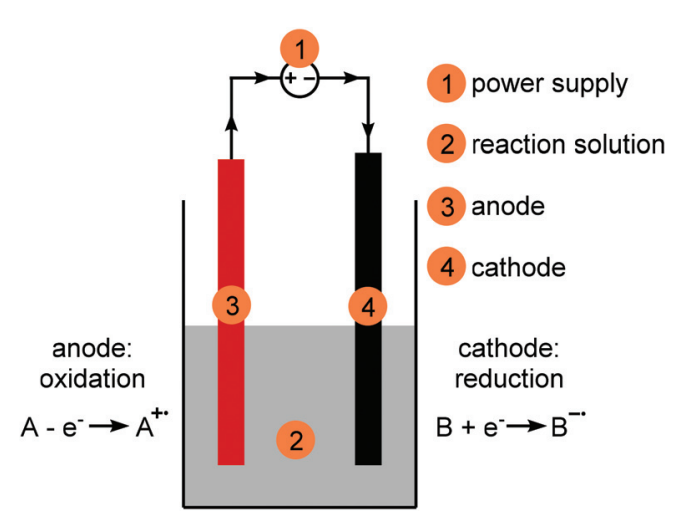

Fig. 1 Simple electrochemical setup for synthesis purposes; red: anode, black: cathode, grey: reaction solution. 
tions, oxidation and reduction, are coupled and one will not happen without the other. The electrode at which the reaction of interest is happening is called the working electrode, the second electrode is called the counter electrode (see section Counter reaction). The electrical circuit is completed through the movement of charged species through the reaction solution.

Electrochemical reactions occur through single electron transfer (SET) to the substrate, usually forming radical species which can then react further to ultimately form a final product. In this respect electrochemistry is based on similar principals as photochemistry. ${ }^{58}$ However, electrochemistry is a heterogeneous process on the electrode surface which means that it can be restricted by the surface area of the electrode.

The electrons are supplied by a power supply (see section Power supply) that pushes electrons from the anode (oxidation electrode) to the cathode (reduction electrode) creating an electrochemical potential. If this potential is greater than the substrate's redox potential, a chemical reaction will happen (Fig. 2a). The flow of electrons is described by the current, which is proportional to the number of electrons transferred. The direction of the current is thereby defined as the opposite to the flow of electrons. The energy to provide the electron gradient is described by the potential. The current describes the rate of electron transfer and is therefore proportional to the stoichiometry of electrons. The potential describes how strongly oxidising and reducing the conditions are (see section Current and potential).

At the electrode surface an electrochemical double layer (Helmholtz layer) is formed (Fig. 2b). ${ }^{59}$ The double layer consists of two layers of charged species of opposite polarities and is formed when an electronic conductor (the electrode material) is in contact with an ionic conductor such as an electrolyte. For example, the anodic double layer consists of a positively charged layer on the electrode surface and a negatively charged layer of the solvated electrolyte that covers the electrode surface. The thickness of the double layer is mostly dependent on the applied voltage and the electrolyte concentration but is typically in a few nanometer scale. The Nernst

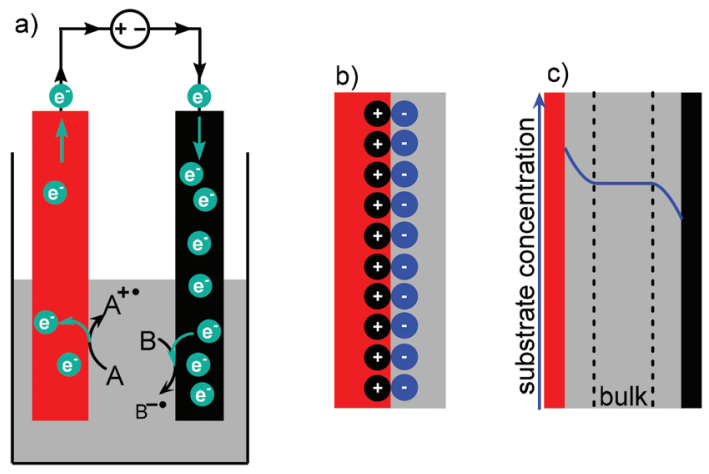

Fig. 2 (a) Movement of electrons in an electrochemical reaction, (b) Helmholtz double layer, (c) Nernst diffusion layer; red: anode, black: cathode, grey: reaction solution. diffusion layer describes the concentration of the substrate near the electrode (Fig. 2c). As the substrate is consumed, the concentration is lower at the electrode compared to the bulk solution resulting in further substrate diffusion towards the electrode. If the substrate is produced, rather than consumed, the concentration is increased near the electrode. So when depositing copper onto a cathode from a sacrificial copper anode, the copper concentration is low at the cathode as it is consumed. However, the copper concentration is high at the anode because it is released from the sacrificial anode. The scale of the diffusion layer is commonly under $0.1 \mathrm{~mm} .^{60}$ Analogous to a traditional heterogeneous reaction, mass transport has to be fast enough to overcome this concentration gradient to allow the reaction to continue. This can for example be achieved through fast enough stirring or narrow electrode gaps.

\section{Counter reaction}

The electrochemical reactions at both electrode surfaces are intrinsically linked. The reaction occurring on the counter electrode is called the counter reaction. The electrons removed at the anode are driven to the cathode by the power supply ensuring a net neutral system. It is important to consider the counter reaction when optimising an electrochemical reaction, as it can be the rate limiting factor in a process. For example, the oxygen evolution in electrochemical water splitting is the rate limiting step, so the substitution to a faster reaction can boost the evolution of hydrogen. In this manner, the oxidation of amines to nitriles as a counter reaction to the reduction of water for hydrogen production has been investigated. ${ }^{61}$

A counter reaction in synthetic chemistry occurring at the cathode is commonly solvent degradation, often deprotonation resulting in hydrogen formation. ${ }^{35,36}$ It can be promoted, for example, by adding a proton donor such as an acid into the system.

A typical counter reaction at the anode is also solvent degradation or the oxidation of a sacrificial metal anode (see section Electrodes) may be used. In addition, sacrificial additives similar to the acid for a cathodic counter reaction can be added when the initial counter reaction is not efficient enough. ${ }^{61}$

\section{Current and potential}

The most important parameters for an electrochemical reaction are the current $(I)$ and the potential $(U)$. The current describes the movement of electrons, the potential describes the energy by which they are moved. The current controls the rate of electrons transferred into the reaction medium and hence the reaction rate. The charge $(Q)$ is the current per unit time and relates to the total number of electrons released into the reaction medium, analogous to a reagent stoichiometry. The energy of the electrons, the potential, needs to be adjusted to the potential of the desired process. Most synthetic reactions occur at potentials up to $2 \mathrm{~V}$. If the potential is too low, the reaction will not happen, and if it is too high then selectivity issues might arise. The current and potential are related 
by the resistance $(R)$ in a process. This resistance is an adduct of various components of the process, such as the wiring and the electrodes, but by far the biggest contributors are the reaction solution and the reaction itself. All three parameters, the potential, resistance and current, are linked and one cannot be changed without the other.

$$
U=R \cdot I
$$

$U$ : potential in volt $[\mathrm{V}], R$ : resistance in ohm $[\Omega], I$ : current in ampere [A].

Reactions can be run under constant current, termed galvanostatic, or constant potential, termed potentiostatic conditions. It is not possible to control both the current and the potential separately without changing the resistance of the setup, which is challenging practically. Both sets of conditions have advantages and disadvantages which will be further discussed in the next sections (for a summary see Table 1).

Galvanostatic conditions. Typically, a galvanostatic setup is relatively simple as only the working and the counter electrode are required, and the exact stoichiometry of electrons is known. The total charge $(Q)$ transferred into the reaction is calculated from the current $(I)$ over time $(t)$. The total charge required for the reaction can be calculated from the number of electrons per substrate $(z)$, the number of moles $(N)$ and the Faraday constant.

$$
\begin{gathered}
Q=I \cdot t \\
Q=n \cdot N \cdot F
\end{gathered}
$$

$Q$ : charge in Coulomb $[\mathrm{C}=\mathrm{A} \mathrm{s}], z$ : number of electrons per substrate, $N$ : number of moles [mol], F: Faraday constant [96 $485 \mathrm{~s}$ $\left.\mathrm{A} \mathrm{mol}^{-1}\right]$.

For a specific current the time for the required charge to pass into the reaction can be calculated.

$$
t=\frac{z \cdot N \cdot F}{I}
$$

The time calculated is the time required for one electron equivalent, (equiv., often referred to as $1 \mathrm{~F}$ or $1 \mathrm{~F} \mathrm{~mol}^{-1}$ ), and can be extended to achieve higher electron equivalents.

The Faradaic efficiency ( $n$ ), or current efficiency, describes how many of the electrons transferred into the reaction mixture end up in the product. Equivalents of electrons and the yield are taken into account. This is an effective way to compare reactions with different electron equivalents.

Table 1 Summary of advantages and disadvantages for galvanostatic and potentiostatic conditions

\begin{tabular}{ll}
\hline $\begin{array}{l}\text { Galvanostatic } \\
\text { (constant current) }\end{array}$ & $\begin{array}{l}\text { Potentiostatic } \\
\text { (constant potential) }\end{array}$ \\
\hline+ Easy setup & $\begin{array}{l}\text { - Only reproducible with reference } \\
\text { electrode }\end{array}$ \\
+ Exact equivalents of & $\begin{array}{l}\text { - Equivalents of electrons not } \\
\text { electrons known }\left(\mathrm{F} \mathrm{mol}^{-1}\right)\end{array}$ \\
$\begin{array}{l}\text { directly controlled } \\
\text { - Voltage range not controlled } \\
\text { + Ability to adjust the process } \\
\text { potential to improve selectivity }\end{array}$
\end{tabular}

Faradaic efficiency is calculated from the theoretical charge $\left(Q_{\text {theo }}\right)$ and the experimental charge $\left(Q_{\text {exp }}\right)$. $Q_{\text {theo }}$ describes the charge theoretically required to obtain the amount of observed product, in other words how many electrons ended up in the product, taking the yield into account. The experimental charge $\left(Q_{\text {exp }}\right)$ describes the total charge transferred into the reaction mixture during the experiment, taking the equivalents of electrons used ( $\mathrm{F} \mathrm{mol}^{-1}$ or equiv.) into account.

$$
\begin{gathered}
n=\frac{Q_{\text {theo }}}{Q_{\exp }} \times 100 \% \\
Q_{\text {theo }}=z_{\mathrm{P}} \cdot N_{\mathrm{P}} \cdot F=z \cdot N \cdot Y \cdot F \\
Q_{\exp }=I \cdot t=z \cdot N \cdot F \cdot \text { equiv. } \\
n=\frac{z \cdot N \cdot F \cdot Y}{z \cdot N \cdot F \cdot \text { equiv. }}=\frac{Y}{\text { equiv. }}
\end{gathered}
$$

$n$ : Faradaic efficiency in percent [\%], $Q_{\text {theo }}$ : theoretical charge in Coulomb [C], $Q_{\text {exp }}$ : experimental charge in Coulomb [C], equiv.: electron equivalents, $z_{\mathrm{P}}$ : Number of electrons per product [-], $N_{\mathrm{P}}$ : Number of mols of the product [mol], $Y$ : yield in percent [\%].

The potential is not actively controlled under galvanostatic conditions and, depending on the resistance of the process, will vary to maintain constant current. A high potential means that there is a high resistance between the two electrodes. The resistance and therefore the potential can be decreased by moving the electrodes closer together, adding more electrolyte (see section Electrolytes) or by increasing the electrode surface area. The current density, current per electrode surface area, allows direct comparison between different experimental setups as it standardises the current for the electrode surface area used. Generally, a low current density results in milder reaction conditions due to a decreased potential, which might avoid issues with selectivity and electrode stability. Lowering the current (and increasing the reaction time) will also result in a decreased potential. At high potentials the reaction conditions are more aggressive and undesired reactions may occur. As the current is proportional to the rate of the reaction, a lower current will result in a longer reaction time needed to pass the total charge desired, in addition to lowering the potential. Hence a trade-off between low potential (mild conditions) and reaction time exists. In addition, the effect of a high current heating up the reaction mixture, called joule or ohmic heating, might lead to changes in reaction temperature over time and active cooling could be considered.

Potentiostatic conditions. The potential, often also referred to as voltage, describes the energy required to move electrons from the anode to the cathode to create a potential difference. If this potential difference is big enough, the electrons can be transferred from the cathode into the reaction solution. At the same time electrons will be removed from the reaction solution at the anode resulting in a current flowing. Analogously to galvanostatic conditions, under potentiostatic conditions the current is not actively controlled and will vary to maintain a constant potential. As the current is usually not constant, elec- 
tron equivalents cannot be calculated directly. If electron equivalents are to be calculated, a multimeter recording the current over time must be included in the setup. Integration of the current over the reaction time will then allow calculation of the electron equivalents. The potential observed is a total potential resulting from the inherent setup resistance (see section Setup of an electrochemical reactor) and the chemical reaction. In order to separate these two processes a reference electrode, which is not involved in the reaction but measures the potential at the working electrode, must be used. In the presence of a reference electrode the potential required for the desired transformation can be directly dialled into the potentiostat (see section Power supply) resulting in a very selective process due to a fine control over the potential in the reaction mixture (see section Cyclic voltammetry as an analytical tool). Analogous to how strong a chemical oxidant is, the potential controls how mild or harsh the conditions are and has a major effect on the selectivity of a process. Potentials for the desired redox process can be obtained from tables with standard potentials $\left(E^{\circ}\right)$ or by measuring cyclic voltammograms (see section Cyclic voltammetry as an analytical tool). Tables of standard reduction potentials $E^{\circ}$ for an oxidised species (Ox) being reduced to a reduced species (Red) can be found in the literature. ${ }^{62,63}$ By definition, these standard potentials are obtained under standard conditions $\left(25^{\circ} \mathrm{C}, 1 \mathrm{~mol} \mathrm{~L}^{-1}, 1 \mathrm{~atm}\right)$ against a standard hydrogen electrode (SHE). Typical potential ranges for organic functional groups, redox mediators and solvents are depicted in Fig. 3.

Ordinarily, a higher potential than the standard potential has to be applied for the desired reaction to occur. The difference is derived from reactions typically not being performed under standard conditions and an additional potential to overcome kinetic inhibition, called the overpotential.

As most electrochemical reactions are not performed under standard conditions, it is important to recognise that the con-

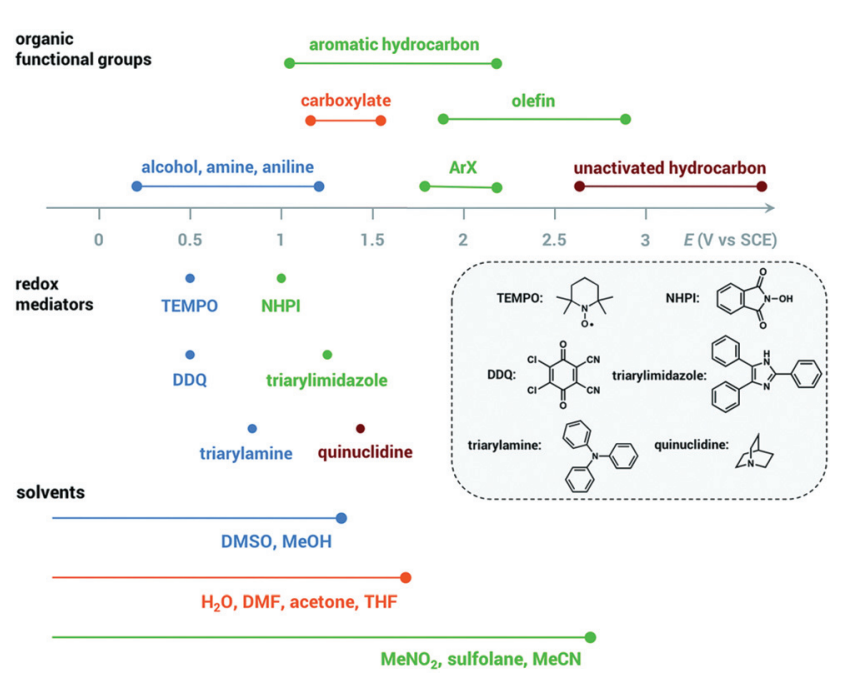

Fig. 3 Oxidation potentials for organic functional groups, redox mediators and solvents, adapted from ref. 66 with permission from The Royal Society of Chemistry. centration has an effect on the redox potential. For a reversible reaction, this relationship is described in the Nernst equation. It assumes that, at a certain potential, both species of the redox couple are in equilibrium.

$$
\begin{gathered}
\mathrm{Ox}+\mathrm{e}^{-} \rightarrow \text { Red } \\
E=E^{\circ}+\frac{R T}{z F} \ln \frac{c_{\mathrm{Ox}}}{c_{\text {Red }}}
\end{gathered}
$$

At $25^{\circ} \mathrm{C}$ this can then be written as:

$$
E=E^{\circ}+\frac{0.059 \mathrm{~V}}{z} \lg \frac{c_{\text {Ox }}}{c_{\text {Red }}}
$$

$R$ : gas constant, $T$ : temperature, $c_{\mathrm{Ox}}$ : concentration of oxidised species Ox, $c_{\text {Red }}$ : concentration of reduced species Red.

Thus, the potential changes as the reaction progresses to a new equilibrium. Assuming a one electron reduction starts under standard condition, at $99 \%$ conversion the equilibrium potential which needs to be overcome can be calculated as:

$$
E=E^{\circ}+\frac{0.059 \mathrm{~V}}{z} \lg \frac{0.01}{0.99}=E=E^{\circ}-0.12 \mathrm{~V}
$$

An increase of $0.12 \mathrm{~V}$ should be expected in the applied potential to maintain the reaction progress.

The overpotential is dependent on the electrochemical reaction and the electrode material. For hydrogen evolution at typical electrode materials, carbon materials have the highest hydrogen overpotential $(\sim-0.6 \mathrm{~V})$, most metal electrodes have a medium overpotential (e.g. $\mathrm{Fe}, \mathrm{Ag}, \mathrm{Ni}, \sim-0.2 \mathrm{~V}$ ) and platinum, palladium and gold have the lowest $(\sim-0.1 \mathrm{~V})$. The investigation of other electrode materials for hydrogen production, such as metal oxide composites, is an active area of research. ${ }^{64}$

When looking at an electrochemical process, both the oxidation and reduction must be considered as the overall potential of the redox system derives from the combination of both cell potentials. For example, if the oxidation requires a potential of $1 \mathrm{~V}$ and the reduction requires a potential of $2 \mathrm{~V}$, then the cell potential will be $3 \mathrm{~V}$.

If a potentiostatic reaction is conducted without a reference electrode, the reaction setup must be reproducible. This is only possible by fully describing the setup, particularly in terms of electrolyte concentration and electrode distance/ arrangement. Nonetheless, such a reaction is likely to suffer from difficulties with respect to reproducibility in a different reaction setup. Reproducing a galvanostatic reaction in a different reaction setup typically has a higher possibility of success. Therefore, a full description of reaction conditions including the reaction setup should be disclosed.

\section{Cyclic voltammetry as an analytical tool}

Cyclic voltammetry (CV) is an analytical tool that is used to determine redox potentials for electrochemical transformations. A well explained guide to CV specifically for synthetic chemists has been prepared by Dempsey and co-workers. ${ }^{56} \mathrm{~A}$ $\mathrm{CV}$ setup comprises of a CV working and counter electrode and a reference electrode. Note that, the working electrode is different than that used in synthetic purposes. During a CV 
experiment the current is measured while the potential at the working electrode is scanned in a cyclic manner using a triangular waveform (see Fig. 4a) resulting in a cyclic voltammogram (see Fig. 4b). If the potential is increased and there is no reaction happening, no increase in current is observed. If a species is present that can be oxidised or reduced under the voltage applied, a current will flow until the species is depleted at the electrode surface resulting in a peak. Depending on the potential window scanned, solvent oxidation and/or reduction might also be observed. The potential at which the maximum current is observed is referred to $E^{\mathrm{a}}$ and $E^{\mathrm{c}}$ for anodic and cathodic respectively. The middle of these two potentials is then the redox potential of the chemical transformation within this system $\left(E^{1 / 2}\right)$. CV helps to understand a redox system and the potential required for a redox event to occur. In this respect, $\mathrm{CV}$ can aid in the elucidation of reaction mechanisms.

Measured potentials are dependent on the type of reference electrode used and will vary significantly when using a different reference electrode (see section Reference electrode). A typical strategy to allow comparison between different systems is to introduce an additional, well-known redox system such as the ferrocene/ferrocenium $\left(\mathrm{Fc} / \mathrm{Fc}^{+}\right)$redox couple. These systems are utilised as internal standards and then referenced to a reference electrode potential. ${ }^{65}$ When recording a cyclic voltammogram, it is important to realise that the first cycle often looks different to repeated cycles. This can be due to passive layers on the electrodes being removed, or deposit on the electrode during a cycle. Therefore, several cycles should be recorded and evaluated. As a starting point a potential where no current is flowing should be chosen. Dependent on

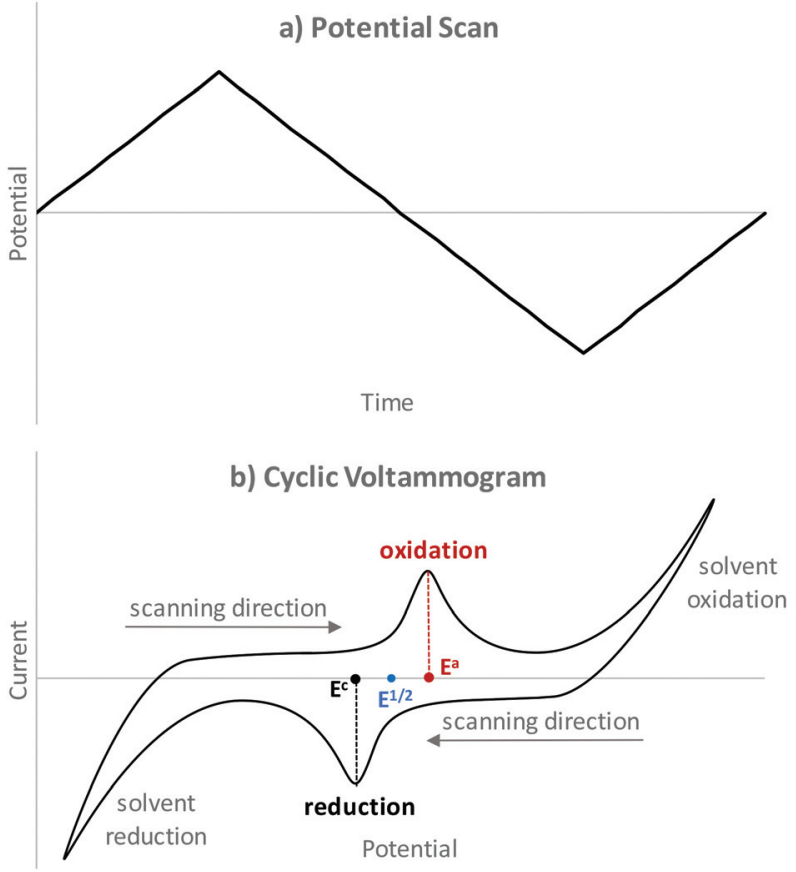

Fig. 4 (a) Cyclic scanning of potential, (b) cyclic voltammogram. the system, the potential scan rate can have a significant effect on the cyclic voltammogram. However, some processes might not be fully reversible so that the reverse peak can be smaller or even disappear completely making the two peaks unsymmetrical. As this is dependent upon the time-scale of the reaction, a faster scan rate can often exhibit semi-reversible processes more clearly.

\section{Setup of an electrochemical reaction}

\section{Power supply unit (PSU)}

The power supply drives the reaction forwards by supplying the electricity to the system and moving electrons from the anode to the cathode. In a way, the power supply acts as the pump of electrons in the system. In the simplest case batteries can be used, however the output voltage and current cannot be controlled easily without extra electronic equipment.

Potentiostats and bench-top power supplies can control either the current or the voltage so that the reaction input can be tailored to the desired conditions (see section Current and potential). Potentiostats generally have further functionality in addition to constant voltage or current and can therefore also be used for electrochemical analytical methods (see section Cyclic voltammetry as an analytical tool). Potentiostats also allow the use of a reference electrode which enables the potential at the working electrode to be controlled precisely. For electrochemical syntheses without using a reference electrode, a bench-top power supply is often sufficient and adequate equipment can be purchased for under $£ 100$ (e.g. Tenma 7210480). Possible alterations include a multichannel power supply or an RS232 adapter for connection to a computer.

\section{Electrodes}

Generally, any conducting material can be used as an electrode. However, depending on the electrode material, size and shape, significant differences in reaction outcome can be observed. As the reactions happen on the electrode surface, the surface area is a significant factor. Foams or meshes have a higher surface area than plates or rods and can therefore be beneficial for a reaction by increasing the reaction rate. As the oxidation and reduction reactions are coupled, both electrode surfaces are important.

Parameters to consider when selecting electrode material are: chemical and electrochemical inertness, promotion of counter reaction and price and availability (see summary in Table 2).

Inertness. When the electrode material is not inert under the reaction conditions, the process might not be reproducible as the electrode changes over time. In addition to chemical inertness, the electrochemical inertness of the electrodes needs to be considered. If the electrode material can be oxidised or reduced, a competing reaction can occur which will use up electrons for an undesired side reaction and decrease the Faradaic efficiency (see section Galvanostatic conditions). This can, for example, happen in an oxidation reaction when 
Table 2 Typical electrode materials and their properties

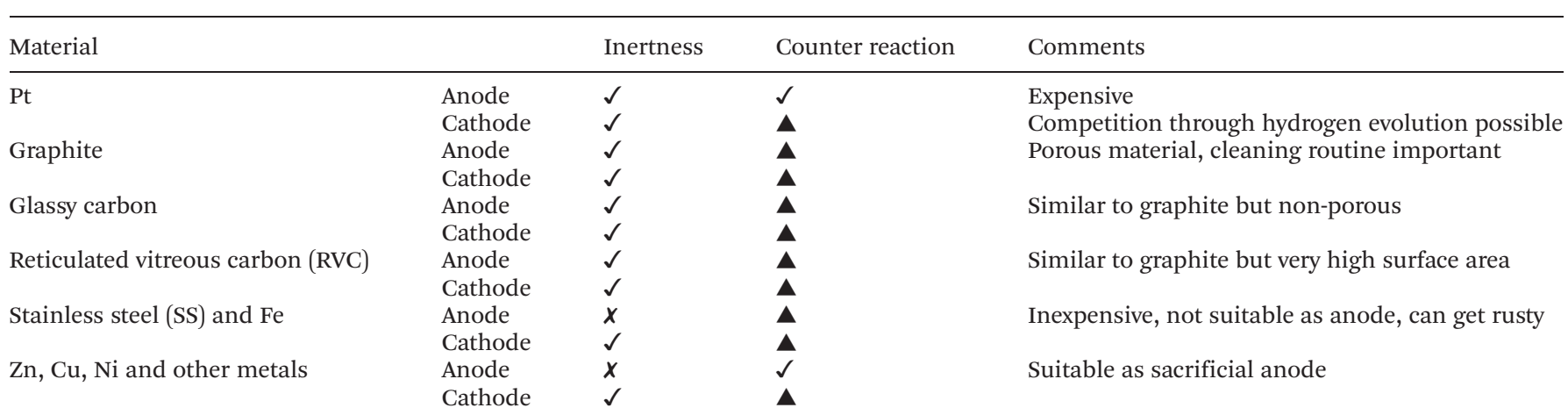

Electrode performance ranked in $\checkmark$ : good, $\boldsymbol{\Delta}$ : medium, $\boldsymbol{x}$ : bad.

easily oxidised metals such as iron or copper are used as the anode. Inert materials for oxidation include: carbon-based electrodes (graphite, glassy carbon, reticulated vitreous carbon) and platinum. For cathodes, most materials are sufficiently electrochemically inert. In a reduction reaction hydrogen evolution can compete with the desired reaction, so electrode materials with large hydrogen overpotential, such as carbon-based electrodes, should be chosen.

Promotion of counter reaction. It is important that the counter reaction is as effective as possible so that the overall reaction rate is not limited by it. The choice of counter electrode is therefore important and needs to promote the counter reaction rate. This can be achieved by increasing the surface area (the counter electrode's surface area should always be at least as big as the working electrode's surface area) and by choosing the right material. For reductions a sacrificial anode made from easily oxidised material can promote the counter reaction by producing metal cations. For this, the desired reaction must tolerate those metal cations. Good examples include copper, zinc or nickel. Other sacrificial reactions or oxygen production are also possible. If the desired reaction is an oxidation, the reduction must also be promoted. In most cases the counter reaction is hydrogen production, with the required potential being dependent upon the material used. It can be promoted by the addition of acids or the use of protic solvents (see sections Solvent and additives).

Reference electrode. A reference electrode (RE) can be used in addition to the working and counter electrode to accurately measure the voltage applied to the working electrode. In this case, the power supply controls the voltage between the reference electrode and the working electrode, which usually have a much smaller distance (and therefore smaller resistance) than the working and counter electrodes. The reference electrode uses a well-defined redox process (such as $\mathrm{Ag} / \mathrm{AgCl}$ ) to accurately measure the potential at the working electrode without taking part in the reaction process itself. Other types of reference electrodes are available and potentials can be interconverted using tables. ${ }^{65}$ However, care should be taken when interconverting potentials as they can be affected by many parameters such as solvent and electrolyte concentration. The use of a reference electrode is important for reproducibility in constant potential reactions (see section Current and potential) and for the performance of cyclic voltammetry (see section Cyclic voltammetry as an analytical tool). Standard bench-top power supplies do not tend to control the potential against a reference electrode, so a potentiostat must be employed.

\section{Batch reactor vessels}

Different setups of the reactor vessel, often referred to as the electrochemical cell, are possible (Fig. 5a). In the simplest case both electrodes are fitted into the same compartment of the vessel, the reaction chamber, and share the reaction solution. This is called an undivided electrochemical cell. This setup can be used if the reaction product is stable under the electrochemical conditions (i.e. is not decomposed on the counter electrode) and is compatible with the counter reaction. Vessels such as beakers or round-bottom flasks have been used (Fig. 5b). ${ }^{67,68}$ However, in these cases the electrodes inevitably will be positioned slightly differently in each setup, with different angles and distances between electrodes which can have an effect on the reaction outcome. Therefore, effort has been made to develop more standardised reaction vessels. Most of these are built in-house with electrodes being fixed in position with seals ${ }^{72-75}$ though more sophisticated solutions including systems for rapid screening have been established. ${ }^{69,70,76,77}$ Access to these reaction setups is often problematic as in-house engineering capacity is necessary. In addition, commercially available equipment has been made available over the last few years (Fig. 5 c). ${ }^{78-80}$ For reactions where the desired and counter reactions are incompatible or the product is not electrochemically stable on the counter electrode, a divided cell should be used. In this case, the reaction chamber is divided into a cathodic and anodic reaction chamber by a membrane or a frit. It is important that the division allows charge transfer, thus ion exchange membranes are often used. Reactors made in-house have been reported ${ }^{81}$ but also commercial reactors consisting of two vessels connected by a bridge, often described as H-cells, are available. ${ }^{78,82,83}$ For potentiostatic experiments (see section Current and potential) 


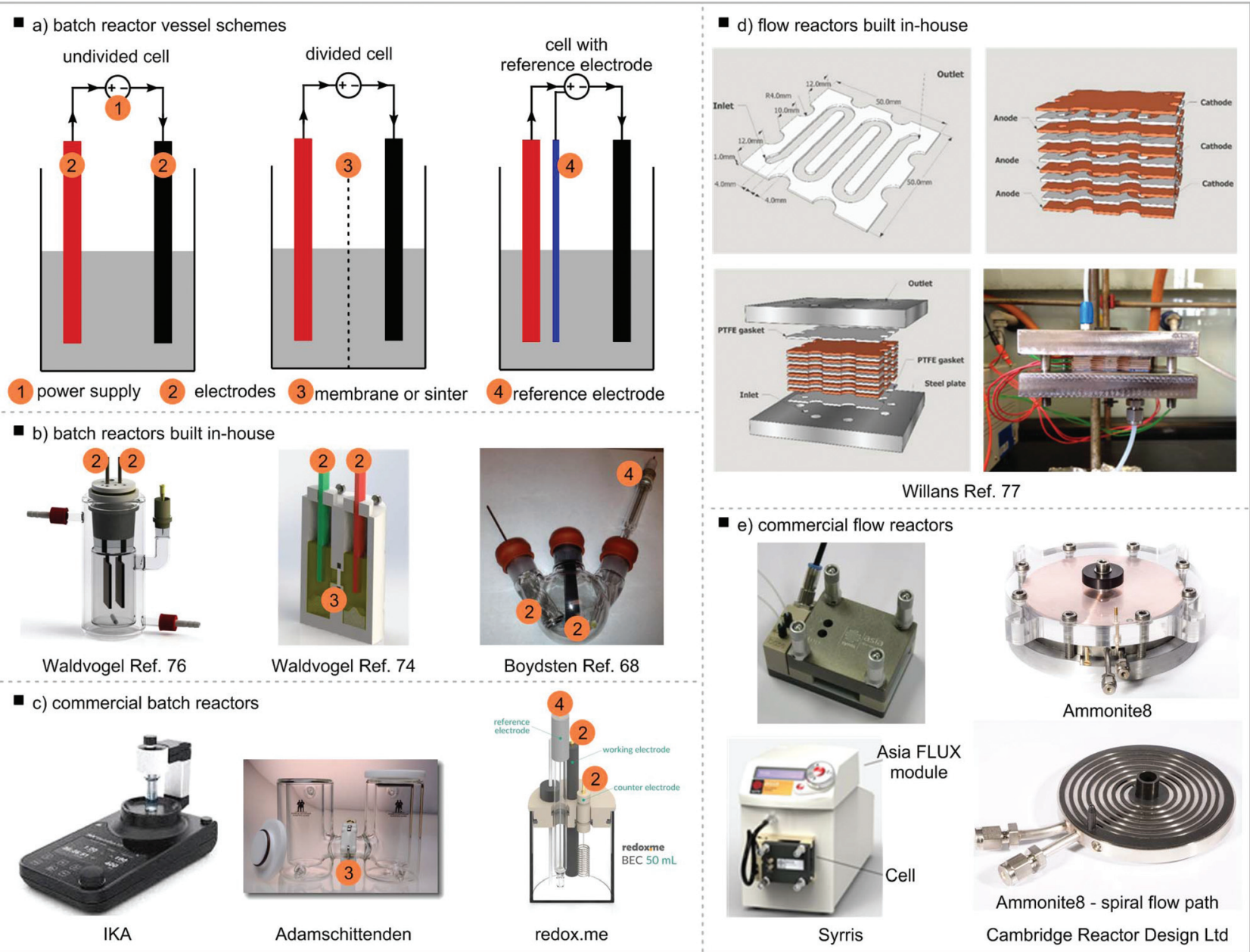

Fig. 5 Electrochemical reactor vessels, (a) batch reactor vessel schemes, (b) batch reactors built in-house, (c) commercial batch reactors, (d) flow reactors built in-house, (e) commercial flow reactors. Undivided cell example: reproduced from ref. 69 with permission from The Royal Society of Chemistry; divided cell example: reprinted with permission from ref. 70 Copyright (2016) American Chemical Society; cell with reference electrode: reprinted with permission from ref. 68 Copyright (2012) American Chemical Society. Willans flow reactor: adapted from ref. 71 with permission from The Royal Society of Chemistry.

a reference electrode must be used. The reference electrode needs to be fitted close to the working electrode.

\section{Continuous reactor vessels}

In addition to batch vessels, continuous flow electrochemical reactors have been developed (Fig. 5d). ${ }^{49-51,84}$ Usually, the two electrodes are separated by a thin spacer that has flow channels cut into it. This allows for a large electrode surface area and a small inter-electrode gap. In general, the large surface area to volume ratio that is enabled by continuous flow reactors provides advantages with respect to heat dissipation as well as energy and mass transfer. As electrochemical reactions are heterogeneous, the larger surface area to volume ratio increases energy transfer from the electrode to the solution as well as mass transfer at the solid/liquid interface. Both these effects provide an increase in the reaction rate. If the reaction is being run under galvanostatic conditions, this will result in lower potentials which allows milder and more selective reac- tion conditions. If the reaction is being run under potentiostatic conditions, this will result in a higher current which will increase the rate of reaction. Due to the electrodes intrinsically fixed in place by a spacer, reproducibility is usually very high in continuous flow electrochemical reactors. The interelectrode gap (typically below $2 \mathrm{~mm}$ ) results in a low overall resistance and in the extreme, even overlapping Nernst diffusion layers where the intermediates themselves can act as the electrolyte. This enhances mass transport and allows reactions to be performed without or with very little additional electrolyte, reducing waste streams and simplifying purification. Another advantage of continuous flow electrochemical reactors is the generation of a homogeneous electric field. While electrochemical batch reactors produce an almost homogeneous electric field between the electrodes, this is not true for the majority of the reaction solution which is not located between the electrodes. Conversely, continuous flow electrochemical reactors generate a homogeneous electric field throughout the 
entire solution as it is entirely situated between the electrodes. Several groups have developed their own continuous flow reactors ${ }^{71,85-99}$ with commercial reactors also being available (Fig. 5e). ${ }^{100-105}$

Brown and co-workers have developed an adjusted equation to calculate the current needed for an electrochemical reaction to suit typical flow parameters (see section Current and potential). ${ }^{106}$ Customarily, the concentration $I$ and the flow rate $(\dot{V})$ are parameters controlled in continuous systems.

$$
I=z \cdot F \cdot c \cdot \dot{V}
$$

$\dot{V}$ : flow rate in millilitre per second $\left[\mathrm{mL} \mathrm{s}^{-1}\right], c$ : concentration in mol per millilitre $\left[\mathrm{mol} \mathrm{mL}^{-1}\right]$.

Generally, electrochemistry benefits from the use of continuous reactors in terms of reaction control (selectivity, yield) but also offers the prospect for direct scale up. We have recently highlighted challenges and benefits in the development of continuous electrochemistry protocols. ${ }^{107}$ In addition, Cantillo and co-workers published a guide to translating batch electrochemistry into single-pass continuous flow conditions. ${ }^{108}$ Continuous electrochemical cells are often used to recirculate batch solutions, however a single-pass layout offers the prospect of telescoping reaction solutions into subsequent reaction or purification steps. The authors also discussed the advantages and disadvantages of potentiostatic vs. galvanostatic conditions and the effects of interelectrode gap, electrolyte concentration, reaction pressure and steady state on the reaction outcome using the example of 4-methylanisole oxidation.

Within our group a flow reactor that uses a $1 \mathrm{~mm}$ PTFE spacer with a flow channel cut in to separate the electrodes has been developed (Fig. 5d). The spacers and electrodes can be stacked to achieve the desired reactor volume and are then held together by two stainless steel plates that are screwed together. $^{71}$ This modular design allows a flexible layout for various applications as the reactor volume and electrode material can easily be varied. In addition, this setup enables straightforward access for cleaning.

\section{Solvent}

Similar to a traditional chemical reaction, the solvent used can have a crucial effect on the outcome of an electrochemical reaction. ${ }^{109}$ In addition to traditional rationale, such as intermediate stabilisation and reagent solubility, the following factors should be considered: solvent window, promotion of counter reaction, stabilisation of intermediates and inherent resistance (conductivity). Typical aprotic solvents are: THF, DCM, MeCN, DMF, DMA and DMSO. Typical protic solvents are (fluorinated) alcohols, such as hexafluoroisopropanol (HFIP), trifluoroethanol (TFE), MeOH and EtOH. Fluorinated alcohols, even as additives to another solvent, can significantly benefit the stability of radicals and so benefit electrochemical reactions. ${ }^{110}$ Commonly, polar solvents are used in electrochemistry as they typically exhibit a lower resistance, so a higher conductivity, than non-polar solvents and usually better dissolve the electrolytes. The use of dry and degassed solvents has to be considered if oxygen reduction or water electrolysis can pose a problem.

The potential range in which the solvent is stable towards oxidation and reduction is called the solvent window (see section Cyclic voltammetry as an analytical tool to determine solvent window experimentally). The solvent window is dependent on the electrode material, electrolyte species and concentration in addition to other factors (see Table 3). The solvent must be stable under the electrochemical conditions employed. If the solvent degrades under the reaction conditions, this can become the primary reaction due to the significantly higher concentration of the solvent compared to the

Table 3 Potentials windows for typical solvents used in synthetic electrochemistry

\begin{tabular}{|c|c|c|c|c|c|}
\hline Solvent & Electrolyte & Electrode & Cathodic limit (V) & Anodic limit (V) & Window (V) \\
\hline \multirow[t]{4}{*}{$\mathrm{H}_{2} \mathrm{O}$} & $0.1 \mathrm{M} \mathrm{KCl}$ & $\mathrm{C}$ & -1.3 & +1.1 & 2.4 \\
\hline & $1 \mathrm{M} \mathrm{KCl}$ & $\mathrm{Hg}$ & -1.7 & 0 & 1.7 \\
\hline & $\mathrm{TBA} \mathrm{ClO}_{4}$ & $\mathrm{Hg}$ & -2.0 & & \\
\hline & $\mathrm{HClO}_{4}$ & $\mathrm{Pt}$ & & +1.5 & \\
\hline \multirow[t]{2}{*}{ MeCN } & $0.1 \mathrm{M} \mathrm{TBA} \mathrm{BF}_{4}$ & $\mathrm{Pt}$ & -3.1 & +3.2 & 6.3 \\
\hline & $\mathrm{LiClO}_{4}$ & $\mathrm{Pt}$ & -3.5 & +2.4 & 5.8 \\
\hline DMF & $0.1 \mathrm{M} \mathrm{TBA} \mathrm{ClO}_{4}$ & $\mathrm{Pt}$ & -2.2 & +1.7 & 3.9 \\
\hline \multirow[t]{2}{*}{ Pyridine } & $\mathrm{LiClO}_{4}$ & $\mathrm{Hg}$ & -1.7 & & \\
\hline & $\mathrm{LiClO}_{4}$ & $\mathrm{C}^{\circ}$ & & +1.4 & \\
\hline DMSO & $0.01 \mathrm{M} \mathrm{TBA} \mathrm{PF}_{6}$ & $\mathrm{Pt}$ & -1.0 & +1.0 & 2 \\
\hline THF & $\mathrm{LiClO}_{4}$ & $\mathrm{Pt}$ & -3.6 & +1.8 & 5.4 \\
\hline \multirow[t]{2}{*}{ DCM } & $0.1 \mathrm{M} \mathrm{TBA} \mathrm{ClO}_{4}$ & $\mathrm{Au}$ & -1.5 & +2.0 & 3.5 \\
\hline & $\mathrm{TBA} \mathrm{ClO}_{4}$ & Pt & -1.7 & +1.8 & 3.5 \\
\hline \multirow[t]{3}{*}{ HFIP } & $0.1 \mathrm{M} \mathrm{TBA} \mathrm{ClO}_{4}$ & $\mathrm{Pt}$ & +0.8 & +2.9 & 2.1 \\
\hline & $0.1 \mathrm{M} \mathrm{TBA} \mathrm{ClO}_{4}$ & $\mathrm{C}$ & -1.6 & +3.1 & 4.7 \\
\hline & $0.1 \mathrm{M} \mathrm{RbF}$ & $\mathrm{C}$ & -1.1 & +3.4 & 4.5 \\
\hline $\mathrm{MeOH}$ & $\mathrm{LiClO}_{4}$ & $\mathrm{Pt}$ & -1.0 & +1.3 & 2.3 \\
\hline \multirow[t]{2}{*}{$\mathrm{MeCOOH}$} & $\mathrm{TEA} \mathrm{ClO}_{4}$ & $\mathrm{Hg}$ & -1.7 & & \\
\hline & $\mathrm{NaOAc}$ & $\mathrm{Pt}$ & & +2.0 & \\
\hline
\end{tabular}

Values referenced to SCE (saturated calomel electrode), taken from the following ref. 110-113. 
substrate, leading to very little conversion of the substrate itself. However, when the reaction is run within the window, a solvent with a low degradation potential can be used. For example, a solvent that degrades at $1.5 \mathrm{~V}$ can be used for a reaction performed at $1.0 \mathrm{~V}$. When performing an oxidation reaction only the oxidative degradation of the solvent is important as it would otherwise compete. The reductive solvent degradation can be a suitable counter reaction. In many cases protic solvents can be a good oxidation solvent as they serve as a proton source, which can be reduced to hydrogen on the counter electrode. In addition, other proton sources such as acids can be added to promote the counter reaction even further (see section Additives).

Practically, the applied overall potential can be bigger than the solvent window as the setup resistance needs to be overcome. In that case, the substrate still has to have a lower potential than the solvent degradation, but the substrate will be consumed first.

\section{Electrolytes}

An electrolyte is added to most electrochemical reactions to decrease the resistance and lower the potential in the system. How much the resistance is lowered is mostly dependent on the concentration of the electrolyte but also on its nature. The most important factor for the electrolyte is its solubility. It must be fully soluble in the reaction mixture. In addition, it should be inert under the reaction conditions, so it does not undergo a redox process under the applied potential. In organic synthesis mostly tetraalkylammonium salts are employed due to their good solubility in organic solvents. The resistance is typically lowest with short alkyl groups and increases with their length. Tetrabutylammonium (TBA) salts are most often found in electrochemical synthesis. Other electrolyte salts can be employed, such as alkali metal salts. Halides, such as $\mathrm{Br}^{-}$and $\mathrm{Cl}^{-}$, can be used as counterions, however they can be oxidised if the potential is too high. Other counterions, such as $\mathrm{PF}_{6}{ }^{-}, \mathrm{BF}_{4}{ }^{-}$ and $\mathrm{ClO}_{4}{ }^{-}$are inert under most electrochemical conditions, but because $\mathrm{ClO}_{4}{ }^{-}$can act as a weak oxidant mostly $\mathrm{PF}_{6}{ }^{-}$and $\mathrm{BF}_{4}{ }^{-}$ are used as electrolyte counterions in electrochemical synthesis. Stoichiometric amounts of electrolyte are usually required to lower the resistance effectively in a batch reactor. With this amount of electrolyte, purification and atom efficiency can become an issue. ${ }^{114}$ In continuous flow reactors (see section Continuous reactor vessel) the required amount of electrolyte can usually be reduced significantly, if needed at all.

\section{Additives}

Additives can be used to enhance the reaction performance further. Mostly, additives either promote the counter reaction or stabilise intermediates. For oxidation reactions the addition of acid can often be beneficial as it acts as a proton source for the reductive release of hydrogen as the counter reaction. Similarly, metal salts can be added to be reduced and deposited on the cathode. Fluorinated alcohols, such as HFIP, can be added to stabilise radical intermediates. ${ }^{109}$ In our systems we use the anode as a sacrificial metal source to form
NHC-metal complexes. $^{67}$ MeCN can stabilise some metal cations such as $\mathrm{Cu}(\mathrm{I})$ and is therefore a good solvent.

\section{Practical reaction setup}

\section{Where to start}

The initial reaction setup should be kept as simple as possible. The following conditions are usually used as a starting point within our group:

- anode: graphite or Pt

- cathode: stainless steel or Pt

- substrate 0.05 to $0.5 \mathrm{M}$

- electrolyte $\mathrm{TBA} \mathrm{BF}_{4} 0.1 \mathrm{M}$

- galvanostatic mode, $50 \mathrm{~mA}, 1-2 \mathrm{~F} \mathrm{~mol}^{-1}$

- monitoring of the reaction by TLC, LCMS etc. over time

Our batch reaction setup (Fig. 6): ${ }^{115}$

- electrode distance: $5 \mathrm{~mm}$

- electrode size $10 \times 50 \mathrm{~mm}^{2}$, submerged surface approximately $10 \times 10 \mathrm{~mm}^{2}$

- $20 \mathrm{~mL}$ solvent

- 1 mmol substrate, $0.5 \mathrm{M}$

- $0.2 \mathrm{mmol} \mathrm{TBA} \mathrm{BF}_{4}, 0.1 \mathrm{M}$

- for $z=1,1.2 \mathrm{~F} \mathrm{~mol}^{-1}, 39 \mathrm{~min}$

\section{Trouble shooting}

We have summarised parameter changes for electrochemical reactions in Table 4 and address typical problems encountered in electrochemical reactions in this trouble shooting section.

Is a current flowing?. If no current is flowing, there is either a connection problem or not enough electrolyte in solution.
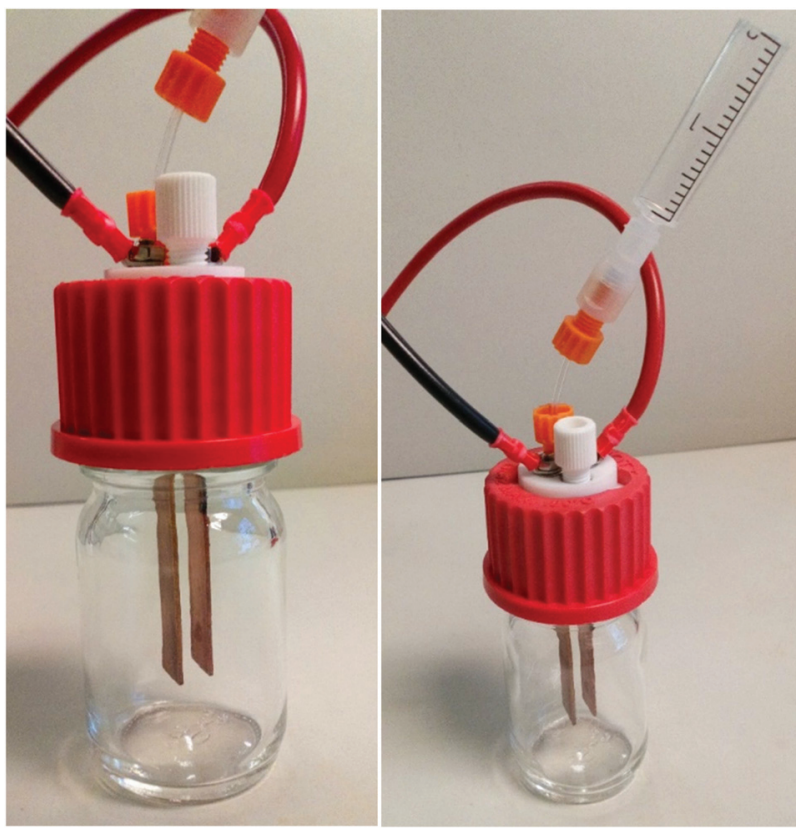

Fig. 6 Our batch reaction setup, reprinted with permission from ref. 115. Copyright 2020 American Chemical Society. 
Table 4 Overview of parameter changes in an electrochemical setup

\begin{tabular}{|c|c|c|c|c|c|c|}
\hline & $\begin{array}{l}\text { Reaction } \\
\text { mode }\end{array}$ & Current & Potential & Resistance & $\begin{array}{l}\text { Reaction } \\
\text { rate }\end{array}$ & Selectivity \\
\hline Current $\uparrow$ & Galvanostatic & $\uparrow$ & $\uparrow$ & Constant & $\uparrow$ & $\begin{array}{l}\text { Potentially compromised due to increased potential } \\
\text { Ohmic heating possible }\end{array}$ \\
\hline Potential $\uparrow$ & Potentiostatic & $\uparrow$ & $\uparrow$ & Constant & $\uparrow$ & Potentially compromised due to increased potential \\
\hline Surface area $\uparrow$ & $\begin{array}{l}\text { Galvanostatic } \\
\text { Potentiostatic }\end{array}$ & $\begin{array}{l}\text { Constant } \\
\uparrow\end{array}$ & $\begin{array}{l}\downarrow \\
\text { Constant }\end{array}$ & $\downarrow$ & $\begin{array}{l}\text { Constant } \\
\uparrow\end{array}$ & $\begin{array}{l}\text { Constant or better } \\
\text { Ohmic heating possible }\end{array}$ \\
\hline Electrode gap $\uparrow$ & $\begin{array}{l}\text { Galvanostatic } \\
\text { Potentiostatic }\end{array}$ & $\begin{array}{l}\text { Constant } \\
\downarrow\end{array}$ & $\begin{array}{l}\uparrow \\
\text { Constant }\end{array}$ & $\uparrow$ & $\begin{array}{l}\text { Constant } \\
\downarrow\end{array}$ & $\begin{array}{l}\text { Potentially compromised due to increased potential } \\
\text { Constant or better }\end{array}$ \\
\hline Electrode gap $\downarrow$ & $\begin{array}{l}\text { Galvanostatic } \\
\text { Potentiostatic }\end{array}$ & $\begin{array}{l}\text { Constant } \\
\uparrow\end{array}$ & $\begin{array}{l}\downarrow \\
\text { Constant }\end{array}$ & $\downarrow$ & $\begin{array}{l}\text { Constant } \\
\uparrow\end{array}$ & $\begin{array}{l}\text { Constant or better } \\
\text { Ohmic heating possible }\end{array}$ \\
\hline Electrolyte concentration $\uparrow$ & $\begin{array}{l}\text { Galvanostatic } \\
\text { Potentiostatic }\end{array}$ & $\begin{array}{l}\text { Constant } \\
\uparrow\end{array}$ & $\begin{array}{l}\downarrow \\
\text { Constant }\end{array}$ & $\downarrow$ & $\begin{array}{l}\text { Constant } \\
\uparrow\end{array}$ & $\begin{array}{l}\text { Constant or better } \\
\text { Ohmic heating possible }\end{array}$ \\
\hline Stirring $\uparrow$ & $\begin{array}{l}\text { Galvanostatic } \\
\text { Potentiostatic }\end{array}$ & Constant & $\begin{array}{l}\downarrow \\
\text { Constant }\end{array}$ & $\downarrow$ & Constant & $\begin{array}{l}\text { Constant or better } \\
\text { Ohmic heating possible }\end{array}$ \\
\hline
\end{tabular}

Before adding electrolyte, first check all connections which can be done using a handheld multimeter. If a problem in the connection is identified, then all connections can be checked manually. Only after checking the connections should more electrolyte be added to decrease resistance or the current increased.

How high is the potential?. We usually aim for an initial potential of about $5 \mathrm{~V}$ ( $5 \mathrm{~mm}$ interelectrode gap). This value will vary with different setups. If the potential is very low, it may not be high enough to afford the desired reaction and the use of less electrolyte might be considered to increase the resistance. A potential similar to or lower than the expected redox potential of the substrate (typically up to $2 \mathrm{~V}$ ) will be too low. If the potential is too high the selectivity of the process can suffer and the use of more electrolyte or a decrease in current might be considered. If the counter reaction is the limiting step, the electrode surface area could be increased, or an additive added to promote the counter reaction. In some cases, restricting the working electrode surface area has resulted in an improved process due to an increased current density and local potential. ${ }^{116}$

Is there any product?. If product is observed, then the reaction can be optimised further similar to a traditional chemical reaction. If there is starting material left, the reaction can be run for longer or the current can be increased to increase the reaction rate. If there is no starting material left but undesired side products are present, i.e. the Faradaic efficiency is low, the selectivity needs to be addressed. The potential should be altered by either lowering the current, adding more electrolyte, increasing the electrode surface area or, if necessary, a divided cell could be used. If this is still not successful, CV should be performed to investigate the redox system further and identify the problem.
How long does the reaction take?. If the reaction time is impractical, the current can be adjusted to either make the reaction time longer (lower current) or shorter (higher current). However, if the current, and thereby the current density, is significantly higher, the electrode material (particularly with graphite) might not be stable enough. Graphite electrodes can disintegrate at high current densities (70-100 mA $\mathrm{cm}^{-2}$ ). In addition, a high current density also leads to heating of the reaction mixture and can therefore have an impact on the reaction outcome. Alternatively, both the current and electrode surface area could be increased.

Is the reaction stable?. Whether the reaction is stable is particularly dependent on the performance of the electrode material under the reaction conditions. A high gas evolution can be problematic for some electrode materials. The use of mechanically stable electrode materials, e.g. glassy carbon or Pt as anode and stainless steel or Pt as cathode can be beneficial. Some electrode materials can be slightly porous, such as graphite or carbon felt, so the use of a glassy carbon electrode can be considered. In addition, electrode surfaces can become inactive due to deposition resulting in a higher resistance over time. Additives, or the use of alternating polarity can overcome these issues. ${ }^{29}$

How to clean the electrodes?. Electrode cleaning can have a major effect on reproducibility and different materials should be treated differently. Metal electrodes, unless they are coated, can be sanded with fine sandpaper (i.e. P1200). Within our group we clean copper electrodes by first wiping with acetone, then sanding, wiping with dilute $\mathrm{HCl}$ (to remove loose copper particles) and rinsing with acetone. Electrodes with a metal coating can only be rinsed and wiped down. Platinum electrodes can be flame cleaned to remove any oxide layer for very sensitive processes. Glassy carbon electrodes can be polished 
with an alumina slurry if necessary but often rinsing is enough. In addition, several cyclic voltammograms with dilute sulfuric acid can clean contaminants within the electrode. Graphite can be slightly porous, so residual reaction mixtures need to be removed. Within our group we employ a cleaning cycle that includes first rinsing the electrode with the reaction solvent and then cleaning it in an ultrasonic bath with reaction solvent, then acid, water and again the reaction solvent.

Galvanostatic vs. potentiostatic?. Within our laboratory we have found that galvanostatic conditions are generally more reproducible and easier to set up under batch conditions (see section Batch reactor vessel), as the electron equivalents can be controlled directly. However, if a reaction suffers from selectivity problems or no conversion at all, switching to a potentiostatic approach with a reference electrode might lead to more success.

Under continuous flow conditions (see section Continuous reactor vessel) potentiostatic conditions are more reproducible for our systems. Due to the small interelectrode gap, the resistance between the two electrodes is small and a potential very close to the desired potential can be used. Cantillo and coworkers have discussed the advantages and disadvantages for galvanostatic and potentiostatic conditions for continuous reactions. $^{108}$

Is the reaction reproducible?. Similar to a traditional chemical reaction, an electrochemical reaction can only be reproducible if all reaction conditions are the same. In addition to traditional reaction conditions such as temperature, reagent purity and concentration, particular attention has to be paid to the reaction setup itself for electrochemical reactions. Most importantly, the electrodes have to be arranged in exactly the same way in terms of distance, angle and solvent submersion (see section Batch reactor vessel). For inter-laboratory reproducibility detailed description of the reaction setup is crucial when reporting setups.

\section{Reaction types (with examples)}

In this tutorial review we have focused on different types of reactions with respect to how and where the elementary redox steps occur rather than on different chemical transformations. This is to highlight different aspects of electrochemical mechanisms that should be considered when developing new methodologies in electrochemistry. The advantages of the setup employed will be discussed for each type of reaction. See the following reviews for specific transformations: cross coupling, ${ }^{24-26} \mathrm{CH}$ activation, ${ }^{27-36}$ asymmetric synthesis, ${ }^{14}$ heterocycle formation, ${ }^{37-39}$ arylation, ${ }^{40}$ fluorination, ${ }^{41}$ organometallic catalysis, ${ }^{42,43}$ cation pool method. ${ }^{44}$

The different types of reactions can be summarised as: (1) direct electrochemical reaction with solvent degradation as counter reaction, (2) direct electrochemical reaction with nonsolvent degradation as counter reaction, (3) mediated or catalysed electrochemical reaction, (4) redox combined electrochemical reaction (Fig. 7).

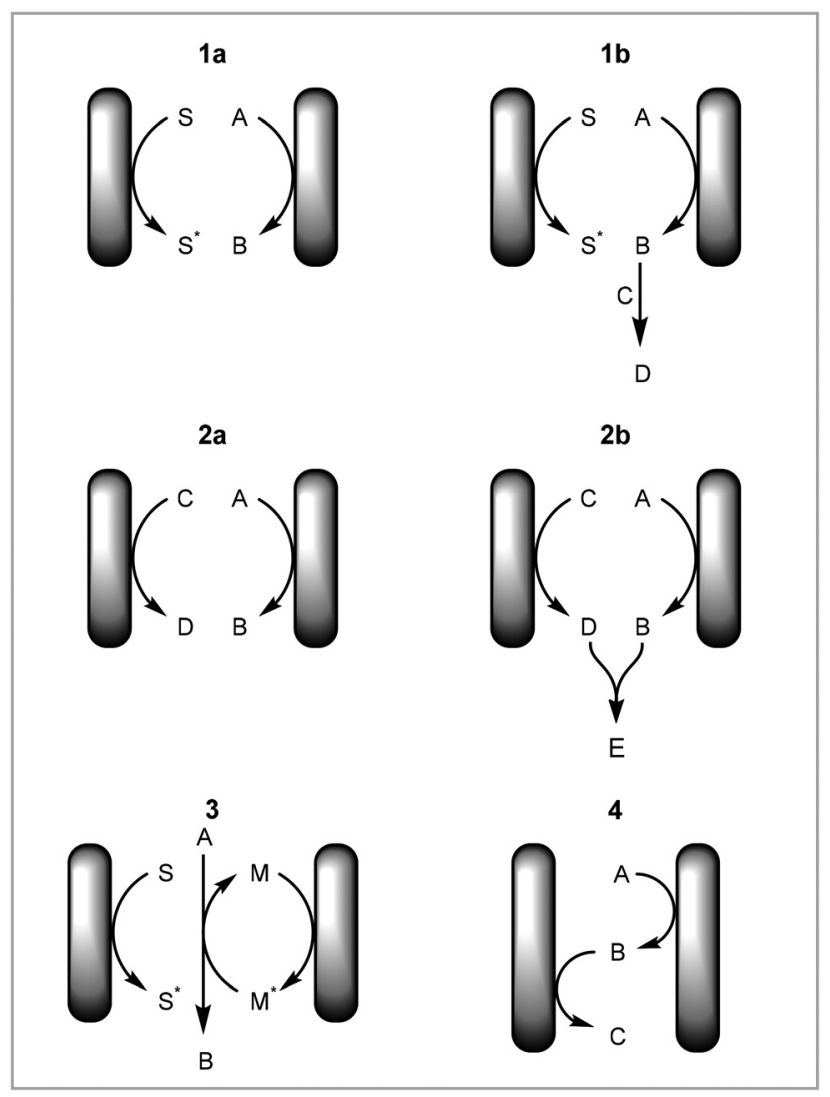

Fig. 7 Types of reactions in electrochemical synthesis; S: solvent, $S^{*}$ : solvent degradation product; $A$ and $C$ : reagents; $B, D$ and $E$ : product; $M$ : mediator or catalyst, $\mathrm{M}^{*}$ : activated mediator or catalyst.

(1) Direct electrochemical reaction with solvent degradation as counter reaction

A direct electrochemical reaction with solvent degradation as the counter reaction is the simplest case of an electrochemical reaction. A substrate is reduced or oxidised on the working electrode and the solvent is degraded as the counter reaction on the counter electrode (Fig. 7, 1a). As most electrochemical reactions produce radicals or other reactive and unstable intermediates, the substrate is very likely to react further to form a new product (Fig. 7, 1b). One example of this is the cation pool method, in which cations are produced electrochemically and after completion of this step a nucleophile is added to afford a new product. ${ }^{44}$

Wirth and co-workers have recently published an example of hypervalent iodine production from the oxidation of iodobenzene (Scheme 1). ${ }^{117}$ Fluorinated alcohols, either TFE or HFIP, were used as solvent. These functioned as the proton source for hydrogen evolution as the counter reaction and in addition the alkoxide then becomes a ligand on the iodine(III) compound. This reaction was performed in a continuous reactor to increase the productivity and then telescoped into a second continuous reactor, thereby coupling the electrochemical step with an oxidation reaction. In this manner the group has demonstrated the electrochemical synthesis of two 


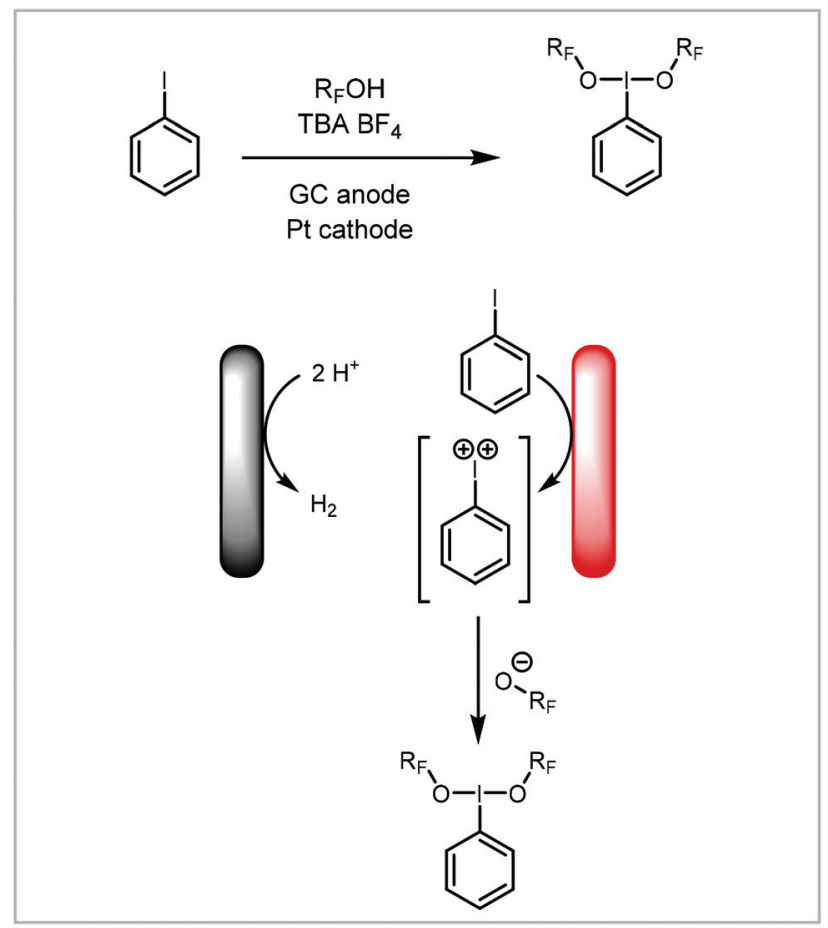

Scheme 1 Electrochemical formation of hypervalent iodine compounds reported by Wirth and co-workers. ${ }^{117}$

hypervalent iodine compounds. These were then used to either oxidise a substrate or to produce bench-stable hypervalent iodine compounds via ligand exchange.

Another example of the direct electrochemical reaction with solvent degradation as the counter reaction is the electrochemical formation of sulfonamides from amines and thiols reported by Noël and co-workers where the acidic, aqueous solution produces hydrogen at the cathode (Scheme 2). ${ }^{75}$ This process requires both starting materials to be oxidised, to the amine cation radical and disulfide respectively before combining to the sulfinamide. This is further oxidised to the sulfonamide via the sulfenamide. The reaction benefits from simple starting materials and mild synthetic conditions. The reaction has been performed both under batch and continuous conditions depending on the substrate and product properties. Generally, the reaction exhibited improved control and higher yields under continuous conditions, however for some examples solubility posed a problem and the reaction was performed in batch.

(2) Direct electrochemical reaction with non-solvent degradation as counter reaction

The counter reaction can be a reaction other than solvent degradation (Fig. 7, 2a). This can be particularly beneficial if (a) the counter reaction is rate limiting or is incompatible with the desired reaction, (b) the counter reaction can produce another useful material or (c) the products from both electrodes react to form a new product. Atobe and co-workers demonstrated that the counter reaction can be used to increase the efficiency of a process by performing another reaction of inter-

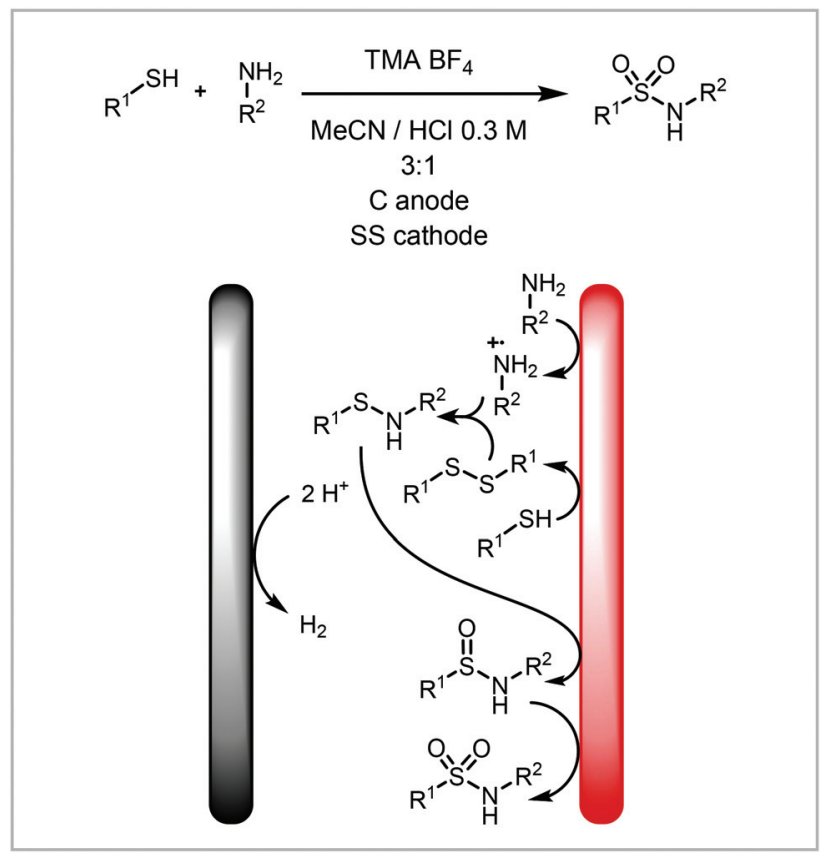

Scheme 2 Electrochemical sulfonamide formation reported by Noël and co-workers. ${ }^{75}$

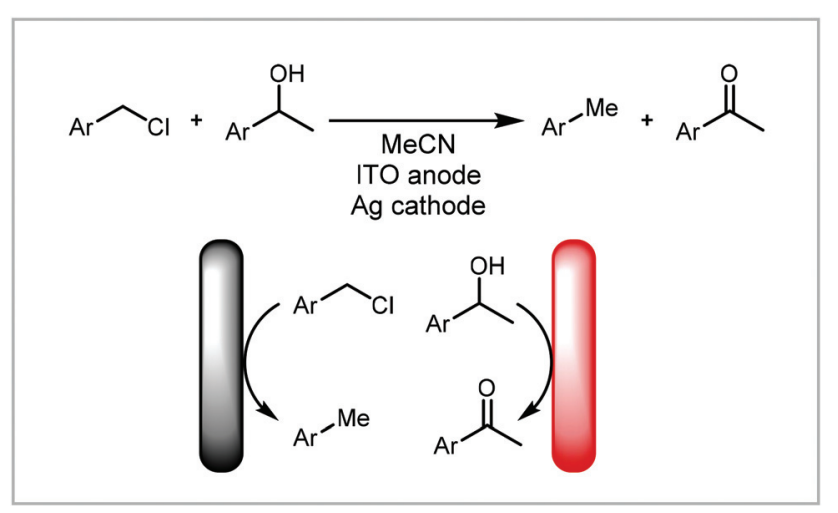

Scheme 3 Paired electrosynthesis reported by Atobe and coworkers. ${ }^{118}$

est in a paired electrosynthesis (Scheme 3). ${ }^{118}$ Concurrent reductive dehalogenation to an alkane and oxidation of an alcohol to a ketone was performed using an indium tin oxide (ITO) anode and a silver cathode. Performing the reaction under parallel laminar flow conditions avoided further reaction of the products at the respective counter electrodes and avoided the use of a divided cell.

In addition to forming two separate products, the synthesis can be coupled by these products reacting further to form a new product (Fig. 7, 2b). Our group has demonstrated the electrochemical formation of NHC-complexes where the an imidazolium salt is reduced to the NHC on the cathode and the anode metal is oxidised to release metal cations into solution (Scheme 4) ${ }^{67}$ The two products then react together to 


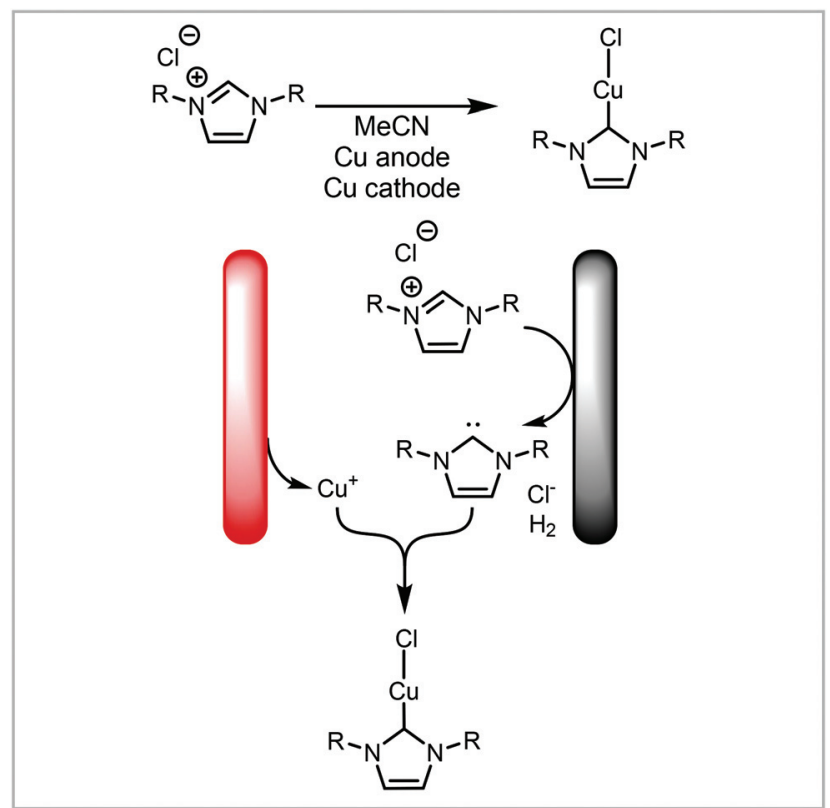

Scheme 4 Electrochemical formation of metal-NHC complexes reported by Willans and co-workers. ${ }^{67,71,119}$

form the NHC complex. This method has been applied to a range of metals and also has been extended to salen ligands. ${ }^{119}$ Benefits of translating this coupled process into continuous flow include increased production rate and Faradaic efficiencies. $^{71}$

\section{(3) Mediated or catalysed electrochemical reaction}

Instead of oxidising or reducing the substrate directly, a mediator or catalyst can be used (Fig. 7, 3). This involves the use of a redox active species which then chemically oxidises or reduces the substrate in solution. This can be beneficial if the substrate's potential would otherwise be outside the solvent window. The use of a mediator or catalyst is very similar to traditional chemocatalysis, except that the catalyst is turned over electrochemically, therefore it is called an electrocatalyst. This avoids the use of terminal reductants or oxidants which improves atom economy and reduces waste streams.

One of the most commonly reported examples of an electrochemical mediator is the use of TEMPO (2,2,6,6-tetramethylpiperidin-1-yl)oxyl and other nitroxyradicals for the oxidation of alcohols. They can be oxidised to the oxoammonium cation which then oxidises the alcohol to a ketone forming a hydroxylamine. This can then be oxidised electrochemically to recover the nitroxyradical (Scheme 5). ${ }^{120}$ Brown and co-workers have developed a continuous flow protocol for the TEMPOmediated electrooxidation of alcohols under particularly mild conditions and without the use of an electrolyte. The group used a carbon on PVDF (polyvinylidene fluoride) anode and a stainless steel (SS) cathode and demonstrated the versatility of the process on the oxidation of 13 substrates.

Likewise, a more traditional catalyst can be used in a mediated electrosynthesis. In this case, the active species of the electrocatalyst is formed and/or turned over by

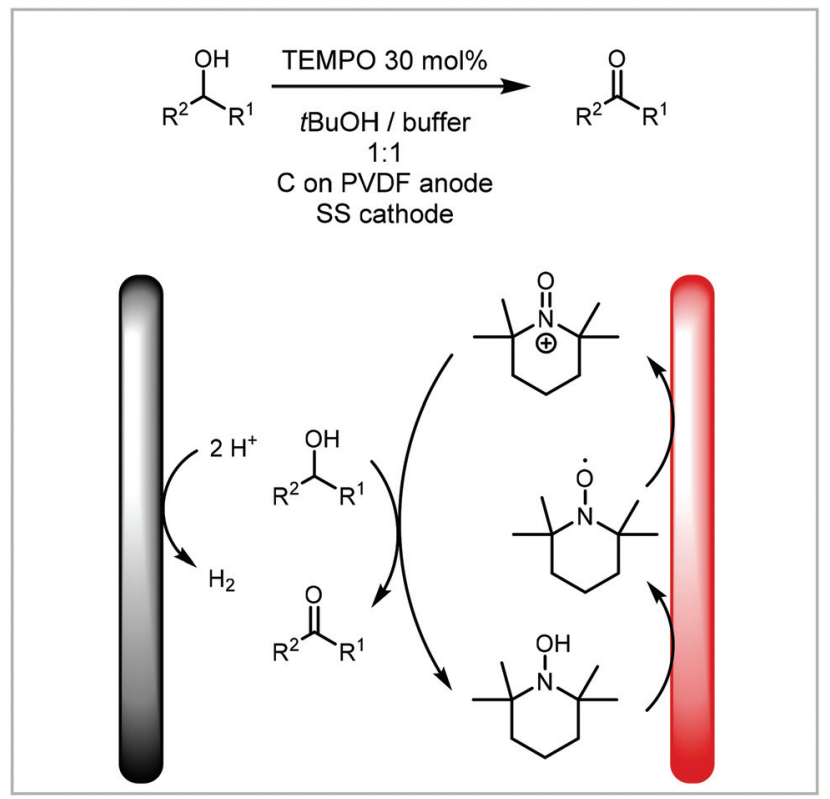

Scheme 5 TEMPO mediated electrooxidation of alcohols reported by Brown and co-workers. ${ }^{120}$

electricity. ${ }^{28,30,32-34}$ This concept has also been applied to photocatalysts. ${ }^{121}$ Morrill and co-workers have developed the electrocatalysed deconstructive chlorination of cycloalkanols (Scheme 6). ${ }^{122}$ The manganese(II) catalyst is activated by addition of a chloride ligand before it is electrochemically oxidised to manganese(III). This species then chemically oxidises an alcohol to an alkoxy radical. After ring-opening, the radical is further oxidised by $\mathrm{Mn}$ (III) to the carbocation which is inter-

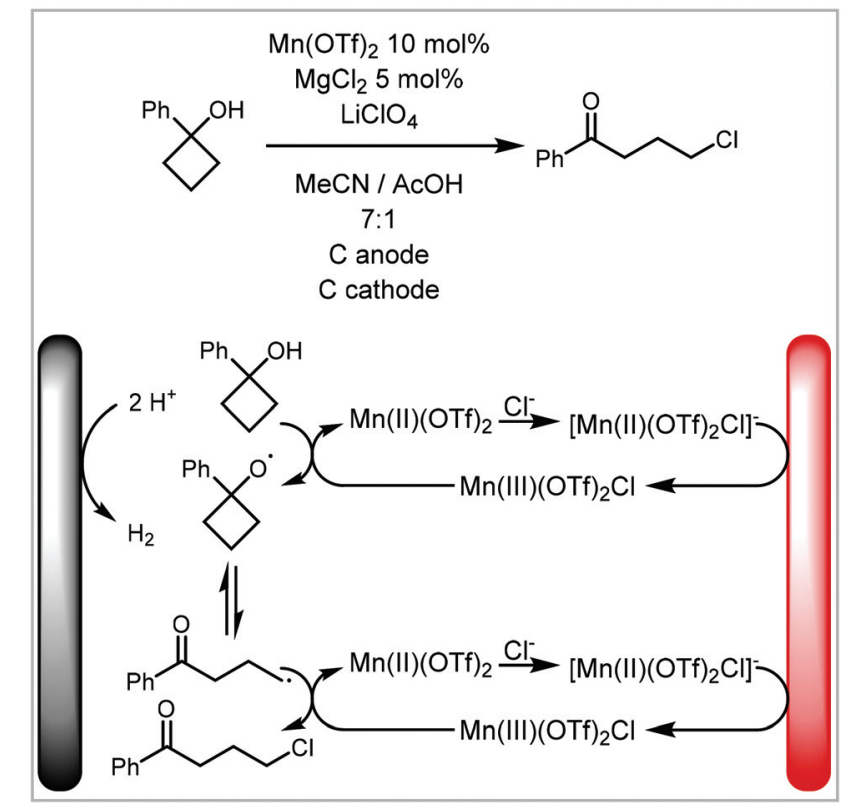

Scheme 6 Manganese electrocatalytic synthesis of cycloalkanols reported by Morrill and co-workers. ${ }^{122}$ 
cepted by chloride to form the final product. The group demonstrated the applicability of this mild electrochemical approach to a broad substrate scope and implemented a continuous protocol including inline purification to increase productivity and scale.

(4) Redox combined electrochemical reaction

A redox combined synthesis, also called domino-oxidationreduction sequence, is a coupled process where the product formed on one electrode reacts further on the other electrode (Fig. 7, 4). ${ }^{123}$ This type of reaction benefits significantly from

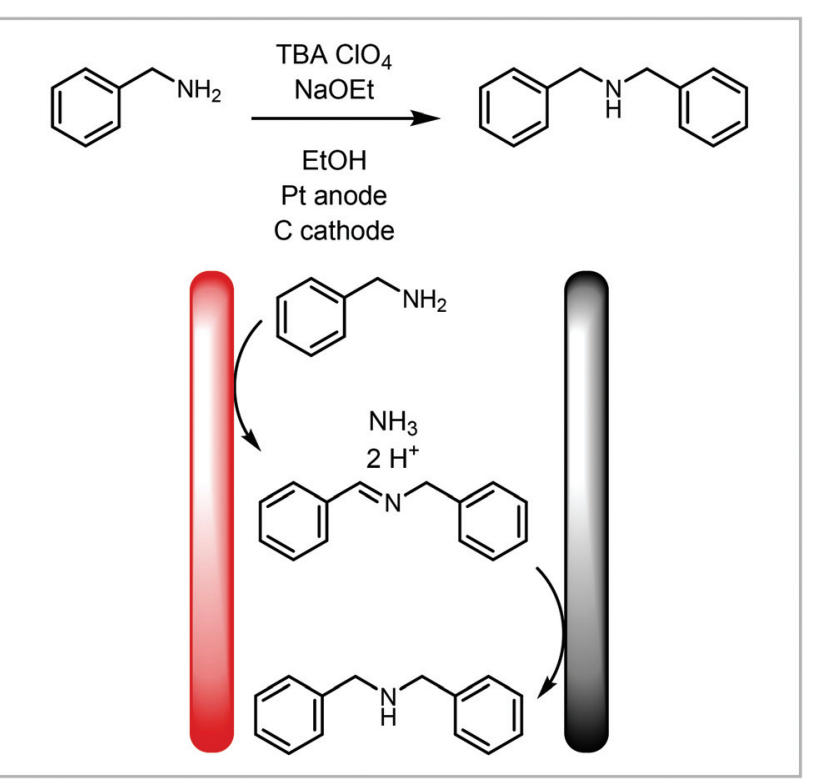

Scheme 7 Redox combined synthesis to dibenzylamine from benzylamine reported by Atobe and co-workers. ${ }^{124}$

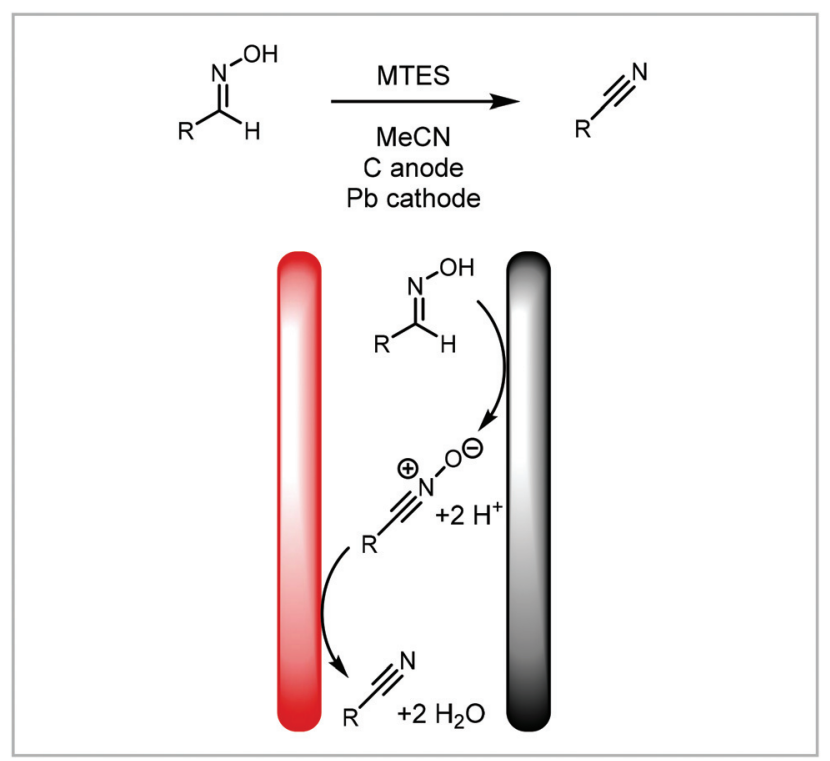

Scheme 8 Domino-oxidation-reduction sequence of nitriles from oximes reported by Waldvogel and co-workers. ${ }^{96,125}$ the use of continuous flow methods with small interelectrode gaps as the substrate has to diffuse from one electrode to the other. Atobe and co-workers investigated a redox combined synthesis of dibenzylamine from benzylamine under batch and continuous flow conditions (Scheme 7). ${ }^{124}$ The benzylamine first undergoes an oxidative dimerisation to the imine and then reduction to the dibenzylamine. When performing the reaction in batch, it was found that the reaction does not proceed to the dibenzylamine product but instead stops after the dimerisation, whereas in flow an equilibrium between $N$-benzylidinebenzylamine and dibenzylamine is achieved. This is attributed to the small interelectrode gap in the continuous flow reactor.

Analogously, Waldvogel and co-workers demonstrated the redox combined synthesis of nitriles from oximes via a nitrile$N$-oxide (Scheme 8), ${ }^{125}$ thus avoiding the harsh reaction conditions found in traditional syntheses of this type. Translating the process into a continuous flow protocol increased the reaction yield significantly for challenging substrates such as 2,6dichlorobenzaldoxime from $40 \%$ to $63 \%$. $^{96}$

\section{Conclusion and outlook}

In this tutorial review we have provided an easily accessible, modern introduction to electrochemistry to allow more researchers to explore the use of synthetic electrochemistry. It is aimed at lowering the perceived barrier to adoption of electrochemistry and increase the engagement of synthetic chemists in this exciting field. This tutorial review covers the mechanism and setup of an electrochemical reaction and recommendations on where to start when exploring electrochemistry. Examples to demonstrate the scope of synthetic electrochemistry are given.

Electrochemistry is a sustainable way to achieve functional complexity in a mild, green and atom efficient way as electrons act as the reagents. Even though the use of stoichiometric amounts of electrolyte may be required, it can still offer major selectivity advantages over traditional chemical methods and therefore avoid protection/deprotection steps. As such, electrochemistry deserves the attention of a broader synthetic chemist community.

With nothing more than a power supply, a pair of appropriately selected electrodes and the knowledge contained within this tutorial, the synthetic chemist should feel confident in adopting electrochemistry as part of their synthesis toolkit.

\section{Conflicts of interest}

There are no conflicts to declare.

\section{Acknowledgements}

The EPSRC (grant EP/R009406/1) and the University of Leeds are acknowledged for funding. 


\section{References}

1 H. Lund, J. Electrochem. Soc., 2002, 149, S21-S33.

2 J. B. Sperry and D. L. Wright, Chem. Soc. Rev., 2006, 35, 605-621.

3 J.-I. Yoshida, K. Kataoka, R. Horcajada and A. Nagaki, Chem. Rev., 2008, 108, 2265-2299.

4 B. A. Frontana-Uribe, R. D. Little, J. G. Ibanez, A. Palma and R. Vasquez-Medrano, Green Chem., 2010, 12, 20992119.

5 S. R. Waldvogel and B. Janza, Angew. Chem., Int. Ed., 2014, 53, 7122-7123.

6 E. J. Horn, B. R. Rosen and P. S. Baran, ACS Cent. Sci., 2016, 2, 302-308.

7 M. Yan, Y. Kawamata and P. S. Baran, Chem. Rev., 2017, 117, 13230-13319.

8 D. S. P. Cardoso, B. Šljukić, D. M. F. Santos and C. A. C. Sequeira, Org. Process Res. Dev., 2017, 21, 1213-1226.

9 A. Wiebe, T. Gieshoff, S. Mohle, E. Rodrigo, M. Zirbes and S. R. Waldvogel, Angew. Chem., Int. Ed., 2018, 57, 55945619.

10 S. Mohle, M. Zirbes, E. Rodrigo, T. Gieshoff, A. Wiebe and S. R. Waldvogel, Angew. Chem., Int. Ed., 2018, 57, 60186041.

11 M. Yan, Y. Kawamata and P. S. Baran, Angew. Chem., Int. Ed., 2018, 57, 4149-4155.

12 R. D. Little and K. D. Moeller, Chem. Rev., 2018, 118, 4483-4484.

13 K. D. Moeller, Chem. Rev., 2018, 118, 4817-4833.

14 M. Ghosh, V. S. Shinde and M. Rueping, Beilstein J. Org. Chem., 2019, 15, 2710-2746.

15 Y. Yuan and A. Lei, Nat. Commun., 2020, 11, 802.

16 Q. Jing and K. D. Moeller, Acc. Chem. Res., 2020, 53, 135143.

17 H. J. Schäfer, in Radicals in Organic Synthesis, ed. P. Renaud and M. P. Sibi, Wiley, 2001, pp. 250-297, DOI: 10.1002/9783527618293.ch14.

18 Electrochemistry: Technology, Synthesis, Energy and Materials, Chem. Rev., 2018, 118(9), 4483-4886.

19 S. D. Minteer and P. Baran, Acc. Chem. Res., 2020, 53, 545546.

20 L. R. Faulkner, J. Chem. Educ., 1983, 60, 262-264.

21 P. T. Kissinger and A. W. Bott, Curr. Sep. Drug Dev., 2002, 20, 51-54.

22 D. T. Sawyer, J. L. Roberts Jr. and A. Sobkowiak, Electrochemistry for chemists, Wiley, New York (N.Y.), 995.

23 C. Kingston, M. D. Palkowitz, Y. Takahira, J. C. Vantourout, B. K. Peters, Y. Kawamata and P. S. Baran, Acc. Chem. Res., 2020, 53, 72-83.

24 P. Wang, X. Gao, P. Huang and A. Lei, ChemCatChem, 2019, 12, 27-40.

25 P. Wang, S. Tang, P. Huang and A. Lei, Angew. Chem., Int. Ed., 2017, 56, 3009-3013.

26 J. L. Röckl, D. Pollok, R. Franke and S. R. Waldvogel, Acc. Chem. Res., 2020, 53, 45-61.

27 M. D. Kärkäs, Chem. Soc. Rev., 2018, 47, 5786-5865.
28 L. Ackermann, Acc. Chem. Res., 2019, 53, 84-104.

29 Y. Takahira, M. Chen, Y. Kawamata, P. Mykhailiuk, H. Nakamura, B. K. Peters, S. H. Reisberg, C. Li, L. Chen, T. Hoshikawa, T. Shibuguchi and P. S. Baran, Synlett, 2019, 30, 1178-1182.

30 J. Chen, S. Lv and S. Tian, ChemSusChem., 2019, 12, 115132.

31 Q.-L. Yang, P. Fang and T.-S. Mei, Chin. J. Chem., 2018, 36, 338-352.

32 N. Sauermann, T. H. Meyer, Y. Qiu and L. Ackermann, ACS Catal., 2018, 8, 7086-7103.

33 Y. Qiu, A. Scheremetjew and L. Ackermann, J. Am. Chem. Soc., 2019, 141, 2731-2738.

34 C. Ma, P. Fang and T.-S. Mei, ACS Catal., 2018, 8, 71797189.

35 H. Wang, X. Gao, Z. Lv, T. Abdelilah and A. Lei, Chem. Rev., 2019, 119, 6769-6787.

36 S. Tang, Y. Liu and A. Lei, Chem, 2018, 4, 27-45.

37 R. Francke, Beilstein J. Org. Chem., 2014, 10, 2858-2873.

38 P. Xiong and H.-C. Xu, Acc. Chem. Res., 2019, 52, 33393350.

39 K. Yamamoto, M. Kuriyama and O. Onomura, Acc. Chem. Res., 2020, 53, 105-120.

40 S. R. Waldvogel, S. Lips, M. Selt, B. Riehl and C. J. Kampf, Chem. Rev., 2018, 118, 6706-6765.

41 T. Fuchigami and S. Inagi, Acc. Chem. Res., 2020, 53, 322334.

42 A. Jutand, Chem. Rev., 2008, 108, 2300-2347.

43 K.-J. Jiao, Y.-K. Xing, Q.-L. Yang, H. Qiu and T.-S. Mei, Acc. Chem. Res., 2020, 53, 300-310.

44 J.-I. Yoshida, A. Shimizu and R. Hayashi, Chem. Rev., 2018, 118, 4702-4730.

45 J.-I. Yoshida, Electrochem. Soc. Interface, 2009, 18, 40-45.

46 K. Watts, A. Baker and T. Wirth, J. Flow Chem., 2015, 4, 211.

47 A. A. Folgueiras-Amador and T. Wirth, J. Flow Chem., 2017, 7, 94-95.

48 M. Atobe, Curr. Opin. Electrochem., 2017, 2, 1-6.

49 D. Pletcher, R. A. Green and R. C. D. Brown, Chem. Rev., 2018, 118, 4573-4591.

50 M. Atobe, H. Tateno and Y. Matsumura, Chem. Rev., 2018, 118, 4541-4572.

51 K. Mitsudo, Y. Kurimoto, K. Yoshioka and S. Suga, Chem. Rev., 2018, 118, 5985-5999.

52 A. A. Folgueiras-Amador and T. Wirth, in Flow Chemistry in Organic Synthesis, ed. T. F. Jamison and G. Koch, Georg Thieme Verlag, Stuttgart, 2018 edn, 2018, pp. 147-189, DOI: $10.1055 /$ sos-SD-228-00106..

53 T. Noël, Y. Cao and G. Laudadio, Acc. Chem. Res., 2019, 52, 2858-2869.

54 M. Elsherbini and T. Wirth, Acc. Chem. Res., 2019, 52, 3287-3296.

55 A. A. Folgueiras-Amador and T. Wirth, in Flow Chemistry: Integrated Approaches for Practical Applications, The Royal Society of Chemistry, 2020, pp. 153-198, DOI: 10.1039/ 9781788016094-00153. 
56 N. Elgrishi, K. J. Rountree, B. D. McCarthy, E. S. Rountree, T. T. Eisenhart and J. L. Dempsey, J. Chem. Educ., 2017, 95, 197-206.

57 C. Sandford, M. A. Edwards, K. J. Klunder, D. P. Hickey, M. Li, K. Barman, M. S. Sigman, H. S. White and S. D. Minteer, Chem. Sci., 2019, 10, 6404-6422.

58 R. H. Verschueren and W. M. D. Borggraeve, Molecules, 2019, 24, 2122-2160.

59 H. Helmholtz, Ann. Phys., 1853, 165, 211-233.

60 Á. Molina, J. González, F. Martínez-Ortiz and R. G. Compton, J. Phys. Chem. C, 2010, 114, 4093-4099.

61 Y. Huang, X. Chong, C. Liu, Y. Liang and B. Zhang, Angew. Chem., Int. Ed., 2018, 57, 13163-13166.

62 W. M. Haynes, CRC handbook of chemistry and physics, CRC Press, 2014.

63 H. G. Roth, N. A. Romero and D. A. Nicewicz, Synlett, 2016, 27, 714-723.

64 M. E. G. Lyons, R. L. Doyle, M. P. Browne, I. J. Godwin and A. A. S. Rovetta, Curr. Opin. Electrochem., 2017, 1, 40-45.

65 V. V. Pavlishchuk and A. W. Addison, Inorg. Chim. Acta, 2000, 298, 97-102.

66 L. M. Reid, T. Li, Y. Cao and C. P. Berlinguette, Sustainable Energy Fuels, 2018, 2, 1905-1927.

67 B. R. M. Lake, E. K. Bullough, T. J. Williams, A. C. Whitwood, M. A. Little and C. E. Willans, Chem. Commun., 2012, 48, 4887-4889.

68 E. E. Finney, K. A. Ogawa and A. J. Boydston, J. Am. Chem. Soc., 2012, 134, 12374-12377.

69 T. Gieshoff, A. Kehl, D. Schollmeyer, K. D. Moeller and S. R. Waldvogel, Chem. Commun., 2017, 53, 2974-2977.

70 C. Gütz, B. Klöckner and S. R. Waldvogel, Org. Process Res. Dev., 2016, 20, 26-32.

71 M. R. Chapman, Y. M. Shafi, N. Kapur, B. N. Nguyen and C. E. Willans, Chem. Commun., 2015, 51, 1282-1284.

72 E. J. Horn, B. R. Rosen, Y. Chen, J. Tang, K. Chen, M. D. Eastgate and P. S. Baran, Nature, 2016, 533, 77-81.

73 Y. Kawamata, M. Yan, Z. Liu, D.-H. Bao, J. Chen, J. T. Starr and P. S. Baran, J. Am. Chem. Soc., 2017, 139, 7448-7451.

74 C. Li, Y. Kawamata, H. Nakamura, J. C. Vantourout, Z. Liu, Q. Hou, D. Bao, J. T. Starr, J. Chen, M. Yan and P. S. Baran, Angew. Chem., Int. Ed., 2017, 56, 13088-13093.

75 G. Laudadio, E. Barmpoutsis, C. Schotten, L. Struik, S. Govaerts, D. L. Browne and T. Noël, J. Am. Chem. Soc., 2019, 141, 5664-5668.

76 L. Schulz, M. Enders, B. Elsler, D. Schollmeyer, K. M. Dyballa, R. Franke and S. Waldvogel, Angew. Chem., Int. Ed., 2017, 56, 4877-4881.

77 B. Riehl, K. M. Dyballa, R. Franke and S. R. Waldvogel, Synthesis, 2017, 252-259.

78 redox.me, https://redox.me/, (accessed 16/01/20).

79 P. S. Baran, E. Horn and D. Waldmann, 2018, US 2018/ 0217096 A1, Closure for an Electrochemical Vessel, Electrochemical Vessel and Laboratory Device.

80 IKA, https://www.ika.com/en/Products-Lab-Eq/ElectrochemistryKit-csp-516/ElectraSyn-20-Package-cpdt-20008980/, (accessed 20/01/20).
81 A. G. O'Brien, A. Maruyama, Y. Inokuma, M. Fujita, P. S. Baran and D. G. Blackmond, Angew. Chem., Int. Ed., 2014, 53, 11868-11871.

82 Alvatek, https://www.alvatek.co.uk/h-cell/, (accessed 16/01/ 20).

83 Adams\&Chittenden, http://www.adamschittenden.com/ Gallery.html?category=4, (accessed 16/01/20).

84 A. A. Folgueiras-Amador, A. E. Teuten, D. Pletcher and R. C. D. Brown, React. Chem. Eng., 2020, 5, 712-718.

85 D. Simonsson, J. Appl. Electrochem., 1984, 14, 595-604.

86 C. Vallières and M. Matlosz, J. Electrochem. Soc. India, 1999, 146, 2933-2939.

87 V. Mengeaud, O. Bagel, R. Ferrigno, H. H. Girault and A. Haider, Lab Chip, 2002, 2, 39-44.

88 M. Küpper, V. Hessel, H. Löwe, W. Stark, J. Kinkel, M. Michel and H. Schmidt-Traub, Electrochim. Acta, 2003, 48, 2889-2896.

89 J.-I. Yoshida, Chem. Commun., 2005, 36, 4509-4516.

90 R. Horcajada, M. Okajima, S. Suga and J.-I. Yoshida, Chem. Commun., 2005, 10, 1303-1305.

91 P. He, P. Watts, F. Marken and S. J. Haswell, Lab Chip, 2007, 7, 141-143.

92 A. Attour, S. Rode, A. Ziogas, M. Matlosz and F. Lapicque, J. Appl. Electrochem., 2008, 38, 339-347.

93 K. Watts, W. Gattrell and T. Wirth, Beilstein J. Org. Chem., 2011, 7, 1108-1114.

94 A. Attour, P. Dirrenberger, S. Rode, A. Ziogas, M. Matlosz and F. Lapicque, Chem. Eng. Sci., 2011, 66, 480-489.

95 C. Gütz, M. Bänziger, C. Bucher, T. R. Galvão and S. R. Waldvogel, Org. Process Res. Dev., 2015, 19, 14281433.

96 C. Gütz, A. Stenglein and S. R. Waldvogel, Org. Process Res. Dev., 2017, 21, 771-778.

97 L.-D. Syntrivanis, F. J. d. Campo and J. Robertson, J. Flow Chem., 2018, 8, 123-128.

98 G. Laudadio, W. de Smet, L. Struik, Y. Cao and T. Noël, J. Flow Chem., 2018, 8, 157-165.

99 C. G. W. van Melis, M. R. Penny, A. D. Garcia, A. Petti, A. P. Dobbs, S. T. Hilton and K. Lam, J. Flow Chem., 2019, 6, 4144-4148.

100 R. A. Green, R. C. D. Brown, D. Pletcher and B. Harji, Org. Process Res. Dev., 2015, 19, 1424-1427.

101 CRD, https://www.cambridgereactordesign.com/ammonite/ammonite.html, (accessed 16/01/20).

102 A. A. Folgueiras-Amador, K. Philipps, S. Guilbaud, J. Poelakker and T. Wirth, Angew. Chem., Int. Ed., 2017, 56, 15446-15450.

103 Vapourtec, https://www.vapourtec.com/products/flow-reactors/ion-electrochemical-reactor-features/, (accessed 16/ 01/20).

104 Syrris, https://syrris.com/product/asia-electrochemistryflow-chemistry-system/, (accessed 16/01/20).

105 F. F. Rivera, C. P. de León, J. L. Nava and F. C. Walsh, Electrochim. Acta, 2015, 163, 338-354.

106 R. A. Green, R. C. D. Brown and D. Pletcher, J. Flow Chem., 2015, 5, 31-36. 
107 T. P. Nicholls, C. Schotten and C. E. Willans, Current Opin. Green Sustainable Chem., 2020, accepted.

108 S. Maljuric, W. Jud, C. O. Kappe and D. Cantillo, J. Flow Chem., 2020, 10, 181-190.

109 L. Schulz and S. Waldvogel, Synlett, 2018, 30, 275-286.

110 R. Francke, D. Cericola, R. Kötz, D. Weingarth and S. R. Waldvogel, Electrochim. Acta, 2012, 62, 372-380.

111 O. R. Luca, J. L. Gustafson, S. M. Maddox, A. Q. Fenwick and D. C. Smith, Org. Chem. Front., 2015, 2, 823-848.

112 D. Polcari, P. Dauphin-Ducharme and J. Mauzeroll, Chem. Rev., 2016, 116, 13234-13278.

113 T. Fuchigami, M. Atobe and S. Inagi, Fundamentals and applications of organic electrochemistry: synthesis, materials, devices, John Wiley \& Sons, 2014.

114 C. Stang and F. Harnisch, ChemSusChem, 2016, 9, 50-60.

115 H. R. Stephen, C. Schotten, T. P. Nicholls, M. Woodward, R. A. Bourne, N. Kapur and C. E. Willans, Org. Process Res. Dev., 2020, DOI: 10.1021/acs.oprd.0c00091.

116 J. Xiang, M. Shang, Y. Kawamata, H. Lundberg, S. H. Reisberg, M. Chen, P. Mykhailiuk, G. Beutner, M. R. Collins, A. Davies, M. Del Bel, G. M. Gallego, J. E. Spangler, J. Starr, S. Yang, D. G. Blackmond and P. S. Baran, Nature, 2019, 573, 398-402.
117 M. Elsherbini, B. Winterson, H. Alharbi, A. A. FolgueirasAmador, C. Génot and T. Wirth, Angew. Chem., Int. Ed., 2019, 58, 9811-9815.

118 F. Amemiya, D. Horii, T. Fuchigami and M. Atobe, J. Electrochem. Soc., 2008, 155, E162-E165.

119 M. R. Chapman, S. E. Henkelis, N. Kapur, B. N. Nguyen and C. E. Willans, ChemistryOpen, 2016, 5, 351-356.

120 J. T. Hill-Cousins, J. Kuleshova, R. A. Green, P. R. Birkin, D. Pletcher, T. J. Underwood, S. G. Leach and R. C. D. Brown, ChemSusChem, 2012, 5, 326-331.

121 J. P. Barham and B. König, Angew. Chem., Int. Ed., 2019, DOI: 10.1002/anie.201913767.

122 B. D. W. Allen, M. D. Hareram, A. C. Seastram, T. McBride, T. Wirth, D. L. Browne and L. C. Morrill, Org. Lett., 2019, 21, 9241-9246.

123 C. A. Paddon, M. Atobe, T. Fuchigami, P. He, P. Watts, S. J. Haswell, G. J. Pritchard, S. D. Bull and F. Marken, J. Appl. Electrochem., 2006, 36, 617-634.

124 F. Amemiya, T. Kashiwagi, T. Fuchigami and M. Atobe, Chem. Lett., 2011, 40, 606-608.

125 M. F. Hartmer and S. R. Waldvogel, Chem. Commun., 2015, 51, 16346-16348. 